\title{
The Allometry of Morphology in Flora and Fauna of New Zealand and Offshore Islands
}

\author{
by \\ Carl David Woodhams
}

\begin{abstract}
A thesis
presented to the School of Biological Sciences,

Victoria University of Wellington, in fulfilment of the requirements for the degree of Master of Science
\end{abstract}

Victoria University of Wellington

December 2020 


\section{Acknowledgements}

Prof. Kevin Burns for patience, guidance, and passion. An inspirational teacher whom without I would not have been able to achieve the completion of this thesis.

Thank you to Dr Carlos Lehnebach and the collections team at The Museum of New Zealand Te Papa Tongarewa for being incredibly helpful and accommodating during the weeks of my visit to the WELT herbarium.

A special thank you to Renee Johnson, for your love, patience, and support during all of the ups and downs.

Dr Jay Woodhams, for offering a plethora of advice, feedback, and critiques.

Sharon and Grant Johnson, for your support, hospitality, and generosity.

Oenone and Mike Woodhams, for your support and motivation. 


\section{Contents}

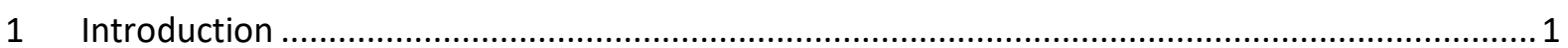

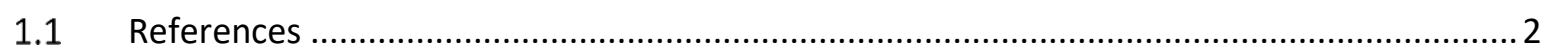

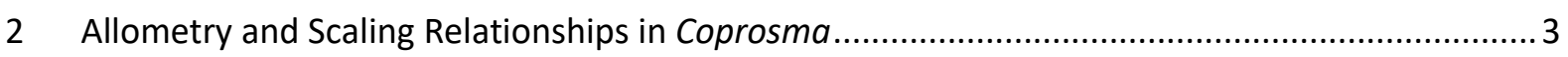

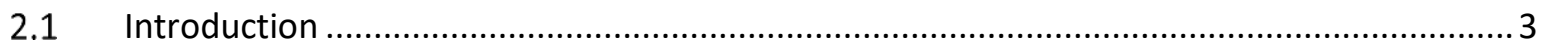

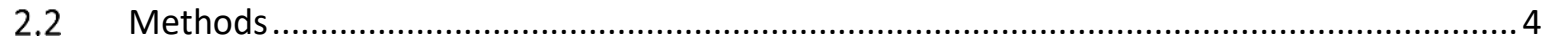

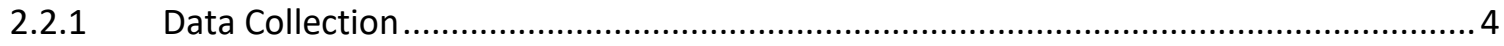

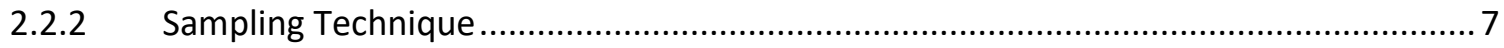

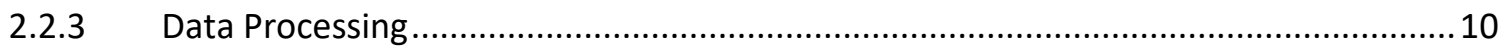

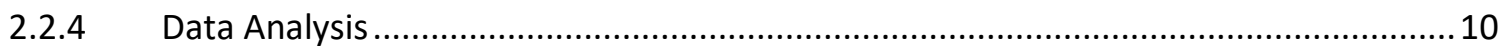

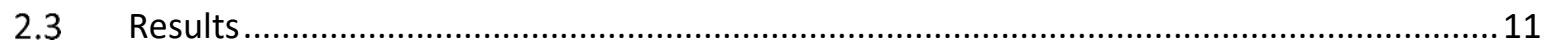

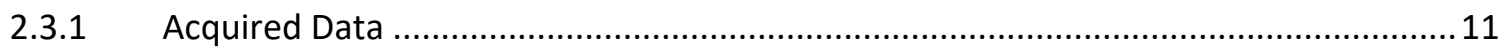

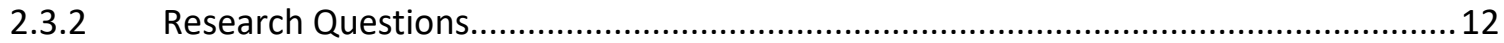

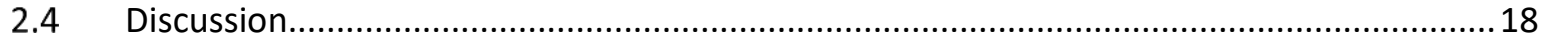

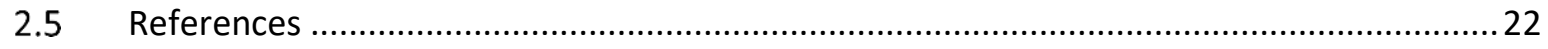

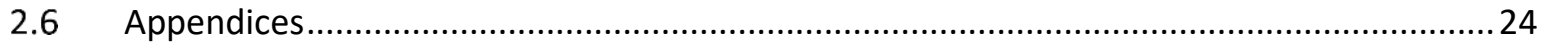

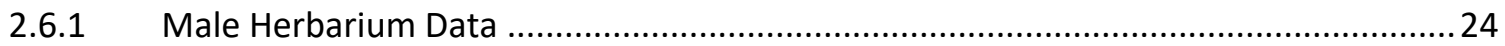

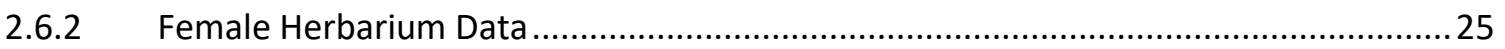

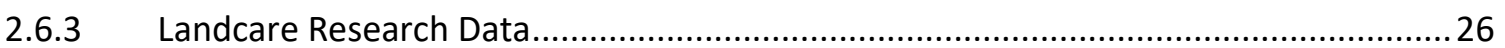

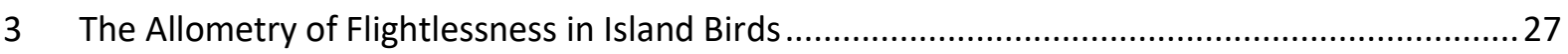

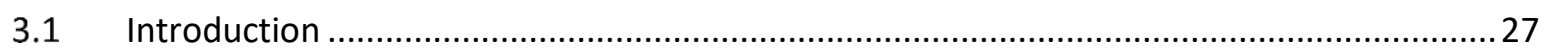

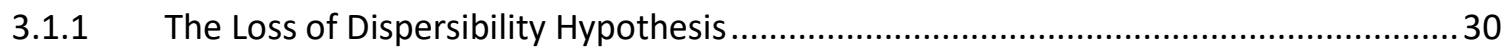

3.1.2 The Size-Constraint Hypothesis ………...................................................................... 31

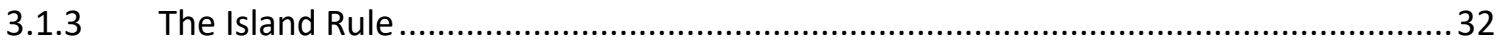

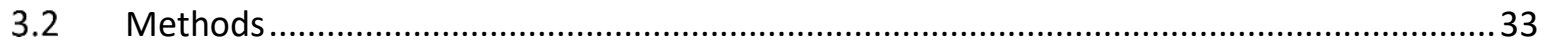

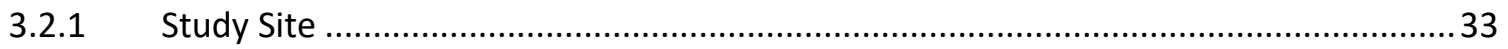

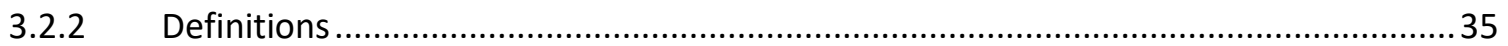

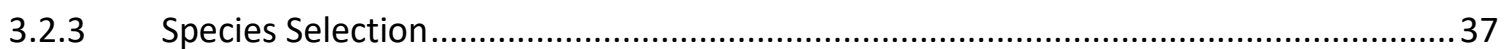

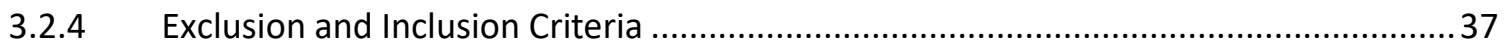

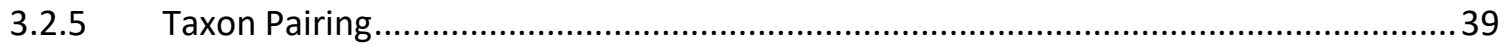

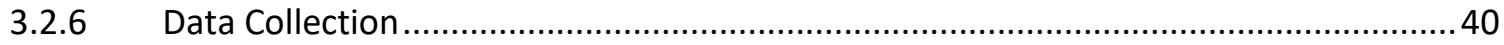

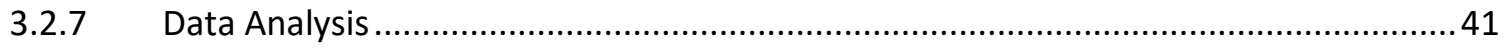

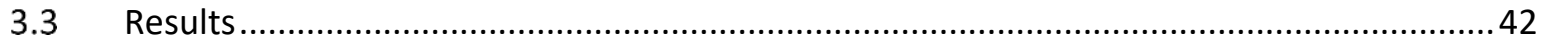




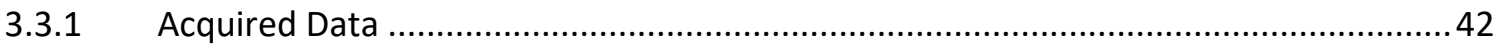

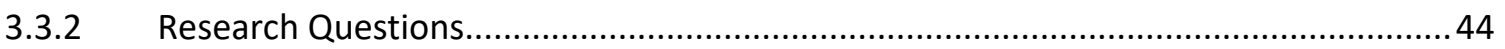

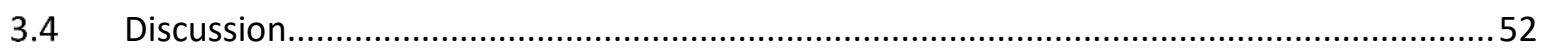

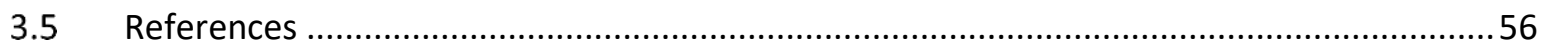

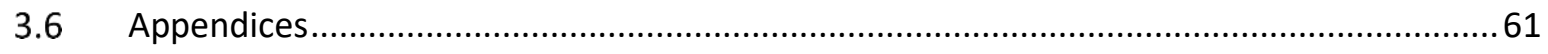

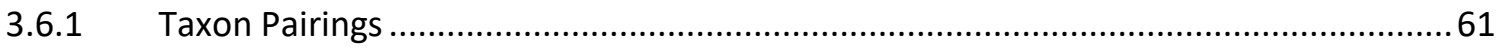

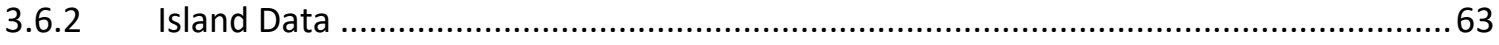

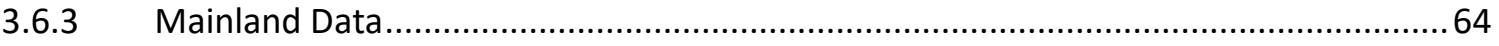

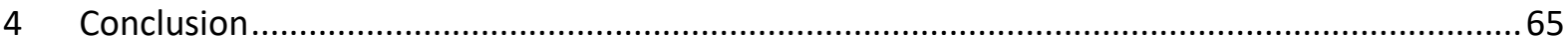




\section{List of Figures}

Figure 2.1 Herbarium specimen example. Kanono, Coprosma grandifolia Hook.f., collected Norsewood, New Zealand. CC BY-NC-ND 4.0. Te Papa (SP023320/B).

Figure 2.2 Sampling technique for each of the features of interest. Figures are sections of Fig 2.1. Kanono, Coprosma grandifolia Hook.f., collected Norsewood, New Zealand. CC BY-NC-ND 4.0. Te Papa (SP023320/B).

Figure 2.3 Petiole width against leaf area. Data points represent one Coprosma species. $\mathrm{X}=\log \mathrm{mm}$. $\mathrm{Y}=\log m m 2$. Males $(\square)$ and Females $(\Delta)$ plotted separately. The graph is fitted with a MA regression line for both males (solid blue) and females (solid red).

Figure 2.4 Petiole Width against seed length for female specimens $(\Delta)$. Data points represent one Coprosma species. $\mathrm{X}=\log \mathrm{mm} . \mathrm{Y}=\log \mathrm{mm}$. The graph is fitted with a MA regression line (solid red).

Figure 2.5 Seed Length against leaf area for female specimens $(\Delta)$. Data points represent one Coprosma species. $\mathrm{X}=\log \mathrm{mm} . \mathrm{Y}=\log m m 2$. The graph is fitted with a MA regression line (solid red).

Figure 2.6 Filament Length against stigma length. Data points represent one Coprosma species. $\mathrm{X}=$ $\log m m . Y=\log m m$

Figure 2.7 Elevation against seed length. Data points represent female specimens from one Coprosma $\operatorname{species}(\Delta) . X=\log m . Y=\log m m$.

Figure 2.8 Elevation against petiole width. Data points represent males $(\square)$ and females $(\Delta)$ of one Coprosma species. $\mathrm{X}=\log m . \mathrm{Y}=\log m m$.

Figure 2.9 Elevation against petiole width. Data points represent females $(\Delta)$ and males $(\square)$ of one Coprosma species. $\mathrm{X}=\log m . \mathrm{Y}=\log m m 2$.

Figure 3.1 Map of New Zealand's coastline during the last glacial period 18,000-20,000 years ago. Retrieved from teara.govt.nz, 23.10.2020.

Figure 3.2 Map of New Zealand and offshore islands. Islands of interest have been highlighted with yellow points. Retrieved from Google Maps, 22/10/2020. .36

Figure 3.3 The wing loading ratio of mainland birds against island birds. Data points represent a taxon pair of an island population with its closest mainland relative. $X=\log \mathrm{cm} / \mathrm{g}, \mathrm{Y}=\log \mathrm{cm} / \mathrm{g}$. The graph is 
fitted with a line of isometry (dashed black) and a MA linear regression line (solid black). Taxon pairs display a majority lean towards the islands.

Figure 3.4 The wing length of mainland birds against island birds. Data points represent a taxon pair of an island population with its closest mainland relative. $X=\log \mathrm{cm}, \mathrm{Y}=\log \mathrm{cm}$. The graph is fitted with a line of isometry (dashed black) and a MA linear regression line (solid black). Taxon pairs display a majority lean towards the islands.

Figure 3.5 The mass of mainland birds against island birds. Data points represent a taxon pair of an island population with its closest mainland relative. $X=\log g, Y=\log g$. The graph is fitted with a line of isometry (dashed black) and a MA linear regression line (solid black). Taxon pairs display a majority lean towards the islands.

Figure 3.6 Island mass over mainland mass against island wing length over mainland wing length. Data points represent a taxon pair of an island population with its closest mainland relative. $X=\log$ island mass over mainland mass, measured in $\mathrm{g} . \mathrm{Y}=$ log island wing length over mainland wing length, measured in $\mathrm{cm}$. The graph is fitted with a line of isometry (dashed black), a MA regression line (solid black), as well as a vertical and horizontal reference lines (solid blue).

Figure 3.7 Island mass over mainland mass against island wing length over mainland wing length. Data points represent a taxon pair of an island population with its closest mainland relative. $X=\log$ island mass over mainland mass, measured in $\mathrm{g} . \mathrm{Y}=\log$ island wing length over mainland wing length, measured in $\mathrm{cm}$. Males $(\square)$ and Females $(\Delta)$ plotted separately. The graph is fitted with a line of isometry (dashed black), an MA regression line for both males (solid blue) and females (solid red), as well as a vertical and horizontal reference lines (solid black).

Figure 3.8 Mainland mass against island wing length over mainland wing length. Data points represent a taxon pair of an island population with its closest mainland relative. $X=\log$ mainland mass, measured in $\mathrm{g} . \mathrm{Y}=\log$ island wing length over mainland wing length, measured in $\mathrm{cm}$. The graph is fitted with a horizontal reference line (dashed black) and a MA regression line (solid black). 50

Figure 3.9 Mainland mass against island mass over mainland mass. Data points represent a taxon pair of an island population with its closest mainland relative. $X=\log$ mainland mass, measured in $\mathrm{g} . \mathrm{Y}=$ log island mass over mainland mass, measured in $g$. The graph is fitted with a horizontal reference line (dashed black) and a MA regression line (solid black). 51 


\section{List of Tables}

Table 2.1 Total number of male and female specimens measured along with number of measurements taken for each feature.

Table 2.2 Regression analysis between variables related to Corner's Rule. Correlations were tested for significance in R Studio with the cor.test function using a pearson distribution.

Table 2.3 Regression analysis between variables related to the relationship between sexes. Correlations were tested for significance with the cor.test function using a Pearson distribution..... 15

Table 2.4 Regression analysis between variables related to the effect of elevation. Correlations were tested for significance with the Im function

Table 3.1 Total number of populations selected via filtration through the exclusion and inclusion criteria. $\mathbf{n}=$ number of populations

Table 3.2 Paired t-test analysis results for Wing Loading Ratio, Wing Length, and Mass for the comparison of male and female island birds.

Table 3.3 MA regression results for Wing Loading Ratio, Wing Length, and Mass for the comparison of male and female island birds.

Table 3.4 Tests for confounding effects on whole data analyses. This table examines each of the analyses for research questions 1 to 5 . \# Sp = the maximum number of populations representative of the same species on the mainland. p1 through p5 are paired t-test $p$-values with one population representative of each mainland species. $n=$ number of populations used in paired $t$-test. 51 


\section{Introduction}

Galileo Galilei first characterised what is now known to be allometry in his 1638 publication titled Dialogues Concerning Two New Sciences, where it was described that larger animals have thicker weight-bearing bones than smaller animals, such as those of elephants with their thick legs that are in stark contrast to mice with legs much smaller (Crew \& de Salvio, 1991; Galilei, 1914). The term 'allometry' was applied by Julian Huxley and Georges Teissier in 1936 as a description of the processes of scaling attributes within the morphology of an organism (Gayon, 2000). Four concepts fall within allometry: ontogenetic allometry, which is relative growth within an individual; phylogenetic allometry, attributed to differential growth ratios within a lineage; intraspecific allometry, describing individuals within a species or local population; and interspecific allometry, referring to relationships between multiple species (Gayon, 2000).

Simply defined, allometry describes the covariance of size, or shape, of an appendage or morphological feature with body size. Allometric scaling is notably distinguishable from isometric scaling. Isometry within this context is a one-to-one scaling relationship of a morphological trait with body size, for example the human heart, which grows isometrically relative to the body at a rate of increase near one to one (Shingleton, 2010). An allometric relationship within the same exemplar is the growth of the human brain, which grows rapidly until a person is around six years old, then slows to where body mass is increasing at a greater rate than brain size throughout the rest of a person's development (Shingleton, 2010).

Allometric scaling has been described to occur in more than an object's dimensions. In 1838, Sarrus and Rameux discussed theories as to why larger animals breathe far slower than smaller animals, with conclusions proposing that an animal experiencing external heat balances produced internal metabolic heat with the heat expelled via the surface of the skin (Sarrus, 2017). These hypotheses were further described by Max Kleiber in the 1930 s, founding his law that suggests metabolic rates scale to the $3 / 4$ power of an animal's mass, an allometric scaling relationship (Shour, 2019).

Today, the applicability of the concept of allometry on the size and function of morphology has been well researched. This thesis explores allometry within the context 
of three primary research objectives: firstly, the effect of mechanistic allometry, the scaling of structural attributes and adherence to Corner's Rule and the Loss of Dispersibility hypothesis; secondly, the exploration of the differences between the sexes on allometric scaling for diecious plants as well as birds; and thirdly, the influence of geography on morphology, with the effect of elevation on plant allometry as well as insularity on the evolution of birds within the context of dispersal ability.

\subsection{References}

Crew, H., \& de Salvio, A. (1991). Galileo Galilei: Dialogues concerning two new sciences. Buffalo, NY: Prometheus Books. (Original work published 1638).

Galilei, G. (1914). Two new sciences (p. 147). Dover.

Gayon, J. (2000). History of the concept of allometry. American zoologist, 40(5), 748-758.

Sarrus, F. (2017). Sarrus and Rameaux, 1838, translated into 365 English by R. Shour. ResearchGate, 366.

Shingleton, A. (2010) Allometry: The Study of Biological Scaling. Nature Education Knowledge 3(10):2

Shour, R. (2019). Why scaling and not dimension, Galileo. Research Gate, 191. 


\section{Allometry and Scaling Relationships in Coprosma}

Abstract A suite of ecological and environmental factors influence plant physiology, with morphology of a plant described by the allometric scaling of structural features abiding Corner's Rule. The aim of this study is to examine three potentially influencing factors on the morphology of plants within the Coprosma genus: the triangular relationship of allometric scaling in leaf, petiole, and seed size, scaling relationships between reproductive structures of male and female flowers in diecious plants, as well as the effect of elevation on the applicability of Corner's Rule on high altitude species. Each of the features across specimens representative of fifty Coprosma species within Te Papa's herbarium collection were measured with callipers and analysed with correlations and regression modelling. The results show that Coprosma species abide Corner's Rule of allometric scaling, however, no relationships were found between floral features of males and females, as well as no evidence for a significant impact of elevation on the applicability of Corner's Rule on high altitude plants.

\subsection{Introduction}

In the mid-20th century Edred John Henry Corner developed the "Durian Theory", following the observations of the Durio zibethinus that has substantially large fruiting bodies (Lauri, 2019). Corner theorised that these fruits would likely be supported by large twigs, and thus crafted two principles of morphology scaling allometrically within plants. The first is the axial conformity rule, that refers to an increased size of the axis or stem in a species coupled with an increased size of the appendages. The second rule refers to a decrease in branch size and thickness with an increase in ramification (Corner, 1949). These complementary principles later became known as Corner's Rules (Lauri, 2019). These rules were further elaborated upon with the discovery of the triangular relationship between stem thickness, leaf area, and seed size. Cornelissen (1998) investigated woody species across the British Isles, measuring seeds, seedlings, leaf area, and stem thickness. Results indicate strong allometric scaling relationships between stem thickness and leaf area, as well as a relatedness between a large seed producing a larger seedling that during maturation produces larger leaves. Conclusively, these three morphological features show evidence for allometric scaling across many woody species. 
Contrarily, allometric scaling is not consistent for some plant species that exhibit sexual dimorphism. In many diecious plants, male leaf sizes are smaller than same-species females (Bond \& Midgley, 1988). This is due to an increase in flowers per inflorescence and the number of inflorescences per plant being greater for male plants than for females. With this increase, a consequence of greater ramification is evident with smaller crosssectional areas of twigs that are not able to support leaves larger than females (Bond \& Midgley, 1988). In relation to floral traits, allometric scaling is evident between features of a flower, such as increase in flower depth correlates with an increase in nectar volume (Klumpers et al., 2017). However, the scaling relationships between structural features of male flowers and those of females for Coprosma are not known.

Alongside the mechanistic restrictions on plant morphology and the differences between the sexes for diecious plants, a third influencing factor on a plant's morphology are geographical and environmental conditions. Species extant at high altitude are often very distinct from closely related low altitude species (Hovenden \& Vander Schoor, 2004). With an increasing altitudinal gradient, trees display changes in morphology and physiology. Physical processes such as atmospheric pressure, air temperature, variation in rainfall, wind exposure impact the morphology of plants (Körner, 2007). In particular, increasing altitude has a large influence on leaf morphology, with an often observed decrease in leaf area at high altitude while simultaneously displaying an increase in leaf lamina and cuticle (Hovenden \& Vander Schoor, 2004).

This study investigates three influencing factors in a plant's morphology: structural allometry, sexual dimorphism, and elevation within a framework of three research questions: (1) Does Coprosma morphology scale allometrically as described by Corner's Rule? (2) Are there significant scaling relationships between floral features of males and females? (3) Do the effects of elevation override Corner's Rule?

\subsection{Methods}

\subsubsection{Data Collection}

Established by Landcare Research (LCR) in 2010, the Coprosma Key is a freely accessible resource that aids the identification of Coprosma species within New Zealand and its territories. The key contains over five hundred images from over thirty-seven plant features tied in with a database of measurements of living plants in situ as well as 
guidance in identification and collecting data from Coprosma species (Glenny et al., 2010). The collated information for this key was drawn from numerous places including published articles in botanical journals and books. As this key provides an accessible overview of all Coprosma species, it is used prominently in this study. To ensure consistency and validity in analyses, the methodology of this investigation is largely replicatory of the methods in which researchers used to produce the data LCR used in the Coprosma Key. However, the key provides no information on floral trait measurements.

To explore the proposed hypotheses, many Coprosma species required measurement. The Museum of New Zealand Te Papa Tongarewa Herbarium (WELT) provided an ample supply of samples to examine plant traits across many preserved specimens. Established in 1865, the WELT herbarium houses over 300,000 dried specimens, with 4,697 belonging to the Coprosma genus, representative of over fifty species. In February 2020, after gaining access to the herbarium, each of these specimens was examined over a twoweek period. Seven key plant traits were selected for measurement. As the central theme of the research revolves around allometric scaling as well as male and female specific traits within a Corposma species, features exclusive and appropriate to explore morphological similarities and differences between sexes were identified. For male plants the filament lengths, anther lengths, and anther widths were measured ( $\mathrm{mm}$ ), and for females the stigma length was measured (mm). Additionally, petiole width, leaf length, and leaf width were also measured for both female and male specimens ( $\mathrm{mm}$ ), to explore potential differentiation in the scaling of non-reproductive structural features and to compare to LCR data. 


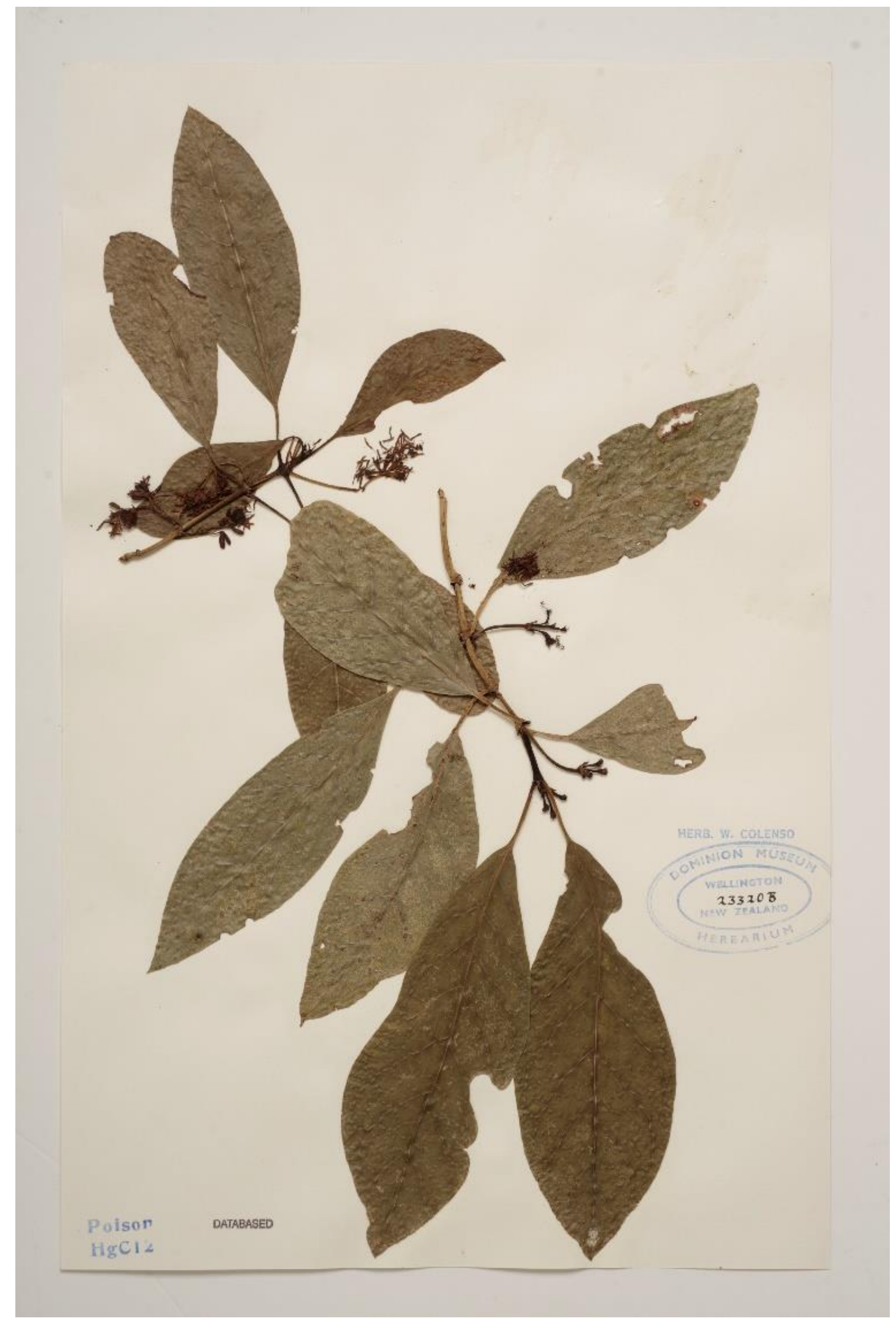

Figure 2.1 Herbarium specimen example. Kanono, Coprosma grandifolia Hook.f., collected Norsewood, New Zealand. CC BY-NC-ND 4.0. Te Papa (SP023320/B). 
All specimens within the Coprosma genus kept at the herbarium were examined. A total of fifty unique Coprosma species were recorded and provided data utilised in this study. This included all subspecies and variations; however, hybrid species were excluded from the study. Up to five specimens were selected per species, with those that did not display floral features being excluded due to not providing relevant data. As sex is the primary variable of interest, the distribution between the sexes of a species were kept relatively even between males and females. Two to three males and two to three females were measured per species except in the circumstance where no males or female examples were present. Coprosma paviflora for example had no male specimens kept within the collection yet was still measured and used in within-female analyses and not in femalemale comparisons.

Upon selection of each specimen, the seven morphological traits were measured. All measurements were conducted in a well-lit area with a pair of callipers that were zeroed before each measurement to ensure accuracy. Specimens were not manipulated or straightened due to their fragility, adhesion to the card, or the toxicity of the biocide mercury chloride $\left(\mathrm{HgCl}_{2}\right)$ that was used to prepare many of the specimens for storing. The method for measuring each trait across all specimens was kept constant throughout the investigation.

\subsubsection{Sampling Technique}

As Corner's Rule describes a triangular relationship between stem, leaf, and seed, the petiole width, leaf length, and seed length were recorded. Despite Corner describing the rule in relation to the stem of the plant, these data were unobtainable from herbarium specimens. This is due to the specimen cuttings being primarily the newest growth on the periphery of the tree, shrub, or bush. Here the width of the petiole was used as a representative value for stem thickness due to Corner's rule of ramification that describes the divergence of stems and limbs into less thick appendages (Lauri, 2019). The thickness of the petiole is likely strongly correlated to the thickness of the plant's stem. Petiole widths were recorded with callipers at a $90^{\circ}$ angle to the nearest $0.01 \mathrm{~mm}$ at the thickest point (Figure 2.2, a.).

The largest leaves within a sample were measured due to the likelihood of their being the oldest growth on a particular clipping. The length of the leaf was measured from the 
attachment node to the stem to the tip of the leaf (Figure 2.2, b.). Widths were measured at a $90^{\circ}$ angle on the widest point of the leaf to the nearest $0.01 \mathrm{~mm}$ (Figure 2.2, c.). Seed lengths were recorded from the LCR Coprosma key database. 
a.

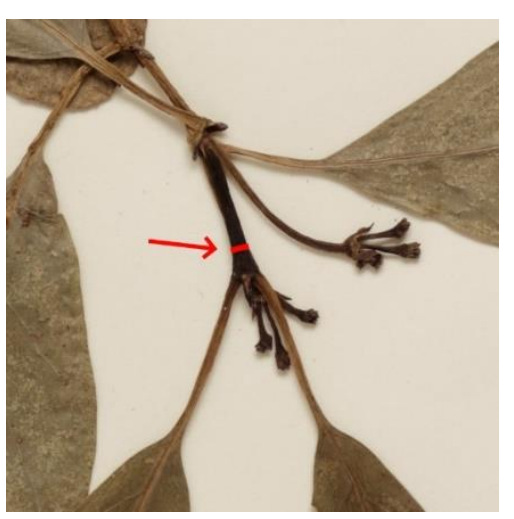

b.

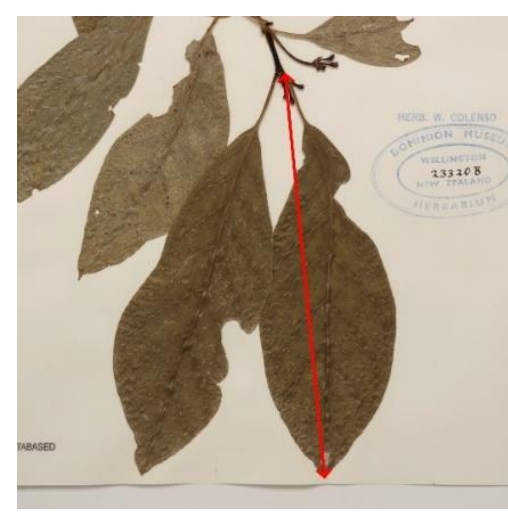

e.
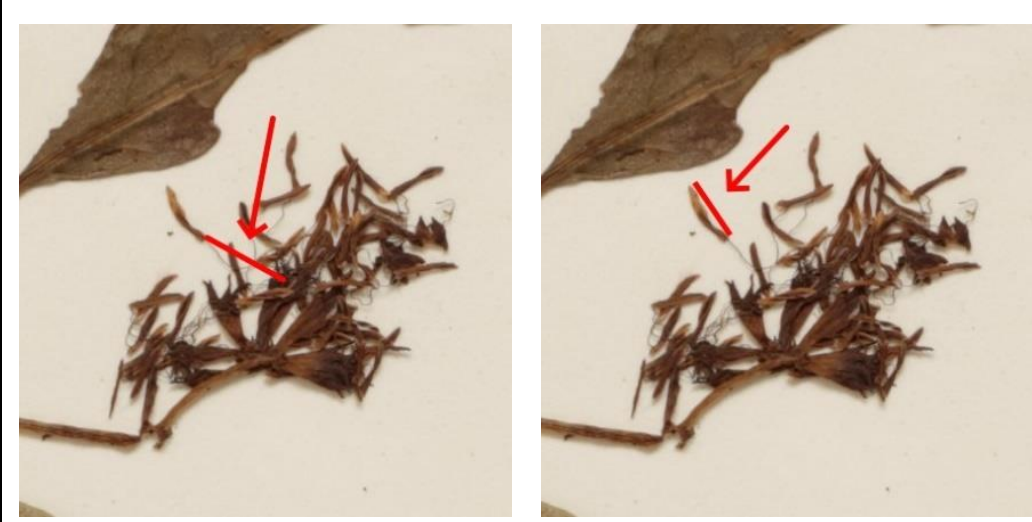

C.

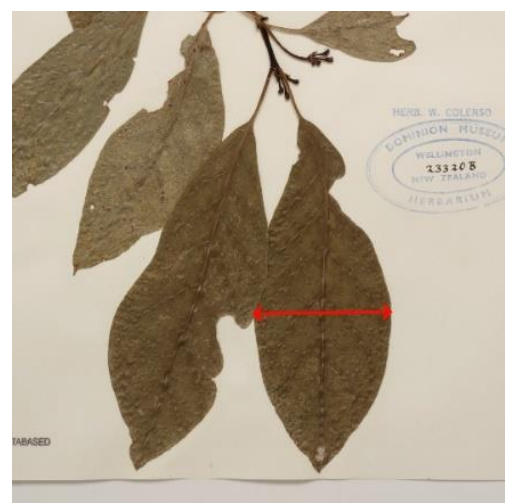

f.

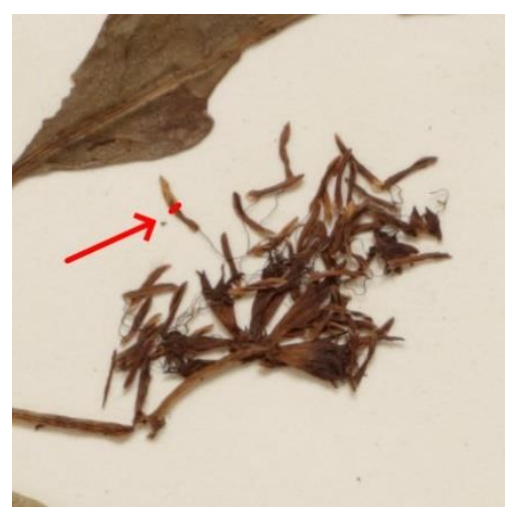

g.

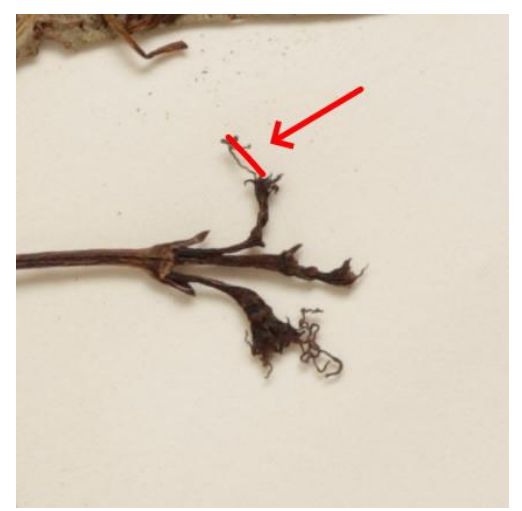

Figure 2.2 Sampling technique for each of the features of interest. Measurements were taken with callipers to the nearest $0.01 \mathrm{~mm}$. Figures are sections of Fig 2.1. Kanono, Coprosma grandifolia Hook.f., collected Norsewood, New Zealand. CC BY-NC-ND 4.0. Te Papa (SP023320/B). 
Three components of male flowers were measured, the filament length, anther length, and anther width to the nearest $0.01 \mathrm{~mm}$. For the filament length, the longest and straightest were selected for measurement due to the dried specimen's fragility if manipulated. The base of the anther to the innermost exposed filament protruding from the flower petals and sepals were measured (Figure 2.2, d.). Anther lengths were measured from the base of the anther to the apex and anther widths from the widest point of the anther (Figure 2.2, e., f.). For female specimens, the stigma length was measured to the nearest $0.01 \mathrm{~mm}$ from the tip to the base of visible protrusion from the sepals. The longest and straightest stigma were selected due to the inability of manipulation (Figure 2.2 , g.)

\subsubsection{Data Processing}

All data was recorded into an Excel spreadsheet along with each specimen's taxonomic classification, specimen number, locality, and sex. Data were processed for accessibility with all male and female data split and averaged separately within each specimen for all feature measurements, then all specimens averaged within a species. For each species, petiole width, leaf length, leaf width, anther length, anther width, filament length, and stigma length were averaged. Additionally, the seed length, seed width, elevation, and maximum plant height measurements that were retrieved from the LCR's Coprosma Key were similarly averaged. For elevation, the mid-point of the minimum and maximum elevation individuals within a species existed was taken to simulate its average.

The averages of leaf area, seed area, and anther area were calculated using the area formula for an ellipse, $A=\pi a b$. Where $a=$ length $/ 2$ and $b=$ width $/ 2$. In excel this involved the formula $=\operatorname{SUM}(($ Leaf Length/2)*(Leaf Width/2)*PIO). The ellipse formula was selected as it best represents of the shape of most Coprosma leaves, seeds, and anthers.

\subsubsection{Data Analysis}

The research questions explore scaling relationships of morphological traits, floral features, and geography, testing the hypotheses of isometric scaling or allometric scaling. Within all testing of significance, the null hypotheses assume that the true mean difference is equal to zero, indicating that there is a significant likelihood that an isometric relationship is apparent and not an allometric or non-relationship. All analyses 
were conducted in the $R$ environment with log transformed data. Data displayed visually was graphed with the ggplot and geom_point functions within the tidyverse and ggplot2 packages (R Core Team, 2020).

Three analyses were undertaken on the data to compare feature relationships. Due to the uncertainty as to the effects of $x$ on $y$ or $y$ on $x$ for many of the comparisons, the correlation coefficients were calculated for all couplings involving morphology. For the effect of elevation, the linear model I regression was used due to the one-way nature of the data, as elevation can affect morphology but not vice versa. Major Axis (MA) regression modelling was utilised to examine the potentiality in scaling relationships for each of the feature tests using the Imodel2 $(y \sim x)$ function within the Imodel2 package.

\subsection{Results}

\subsubsection{Acquired Data}

Over 4,000 specimens were examined for floral features with representation of 50 Coprosma species harvested from all over New Zealand and nearby offshore islands. A vast majority of specimens did not contain any floral features. Suitable male specimens with preserved floral features were also less common than females, with 138 female and 82 male specimens recorded (Table 2.1). From the representatives of each of the species, a total of 5,546 measurements were taken across 220 specimens held within the herbarium's collection. The subjects list consists of taxonomically classified species and sub-species with hybridised species such as Coprosma propinqua A. Cunn x Coprosma robusta excluded from sampling due to potential for morphological disparity.

Table 2.1 Total number of male and female specimens measured along with number of measurements taken for each feature.

\begin{tabular}{lccccccccc} 
Sex & Specimens & $\begin{array}{c}\text { Petiole } \\
\text { Width }\end{array}$ & $\begin{array}{c}\text { Leaf } \\
\text { Length }\end{array}$ & $\begin{array}{c}\text { Leaf } \\
\text { Width }\end{array}$ & $\begin{array}{c}\text { Flowers } \\
\text { Sampled }\end{array}$ & $\begin{array}{c}\text { Stigma } \\
\text { Length }\end{array}$ & $\begin{array}{c}\text { Anther } \\
\text { Length }\end{array}$ & $\begin{array}{c}\text { Anther } \\
\text { Width }\end{array}$ & $\begin{array}{c}\text { Filament } \\
\text { Length }\end{array}$ \\
\hline Female & 138 & 138 & 690 & 689 & 813 & 816 & - & - & - \\
Male & 82 & 80 & 399 & 399 & 379 & - & 381 & 381 & 381
\end{tabular}

A number of sampled species had male representatives but not female and vice versa. Eight species were excluded from the analyses involving male specimens due to not 
having male flowers, including $C$. cheesemanii, $C$. decurva, $C$. distantia, $C$. elatirioides, $C$. parviflora, C. pseudociliata, C. pseudocuneata, and C. virescens. Two species were excluded from the calculations involving female specimens that had no female flowers, $C$. distantia and $C$. intertexta.

\subsubsection{Research Questions}

(1) Does Coprosma morphology scale allometrically as described by Corner's Rule?

The null hypothesis assumes that the difference in feature averages is equal to zero, with the alternative hypothesis suggesting the presence of a scaling relationship between the two features. Three measurable morphological traits were sampled to address the applicability of Corner's Rule on the Coprosma genus (Table 2.2). Male data were excluded for comparisons involving seed length due to the feature only being present on female plants.

Table 2.2 Regression analysis between variables related to Corner's Rule. Correlations were tested for significance in R Studio with the cor.test function using a pearson distribution.

\begin{tabular}{l|llr}
$\boldsymbol{X}$ & $\boldsymbol{Y}$ & Test & p-value \\
\hline Male Leaf Area & Female Leaf Area & cor & $<0.001$ \\
Male Petiole Width & Male Leaf Area & cor & 0.01 \\
Female Petiole Width & Female Leaf Area & cor & $<0.001$ \\
Female Petiole Width & Seed Length & cor & $<0.001$ \\
Seed Length & Female Leaf Area & cor & $<0.001$
\end{tabular}

Across 41 male specimens, cor.test regression of petiole width and leaf area produced a p-value of 0.01 , with an MA regression analysis computing a slope angle of 15.3008 with a $95 \%$ confidence interval (CI) of 8.8625 to 55.0408 , as well as an intercept of -3.2917 , with a $95 \%$ CI of -16.4498 to -1.16 . Similarly, the petiole width and leaf area for 41 female specimens gave a correlation p-value of < 0.001, a MA regression slope of 12.9944 with upper and lower 95\% CI limits of 9.079 to 22.7603, along with an intercept of -2.6829 with a $95 \% \mathrm{CI}$ of -6.0658 to -1.3266 . Graphical representation of the data displays positive correlative association within both male and female specimens for petiole width and leaf area (Figure 2.3). 


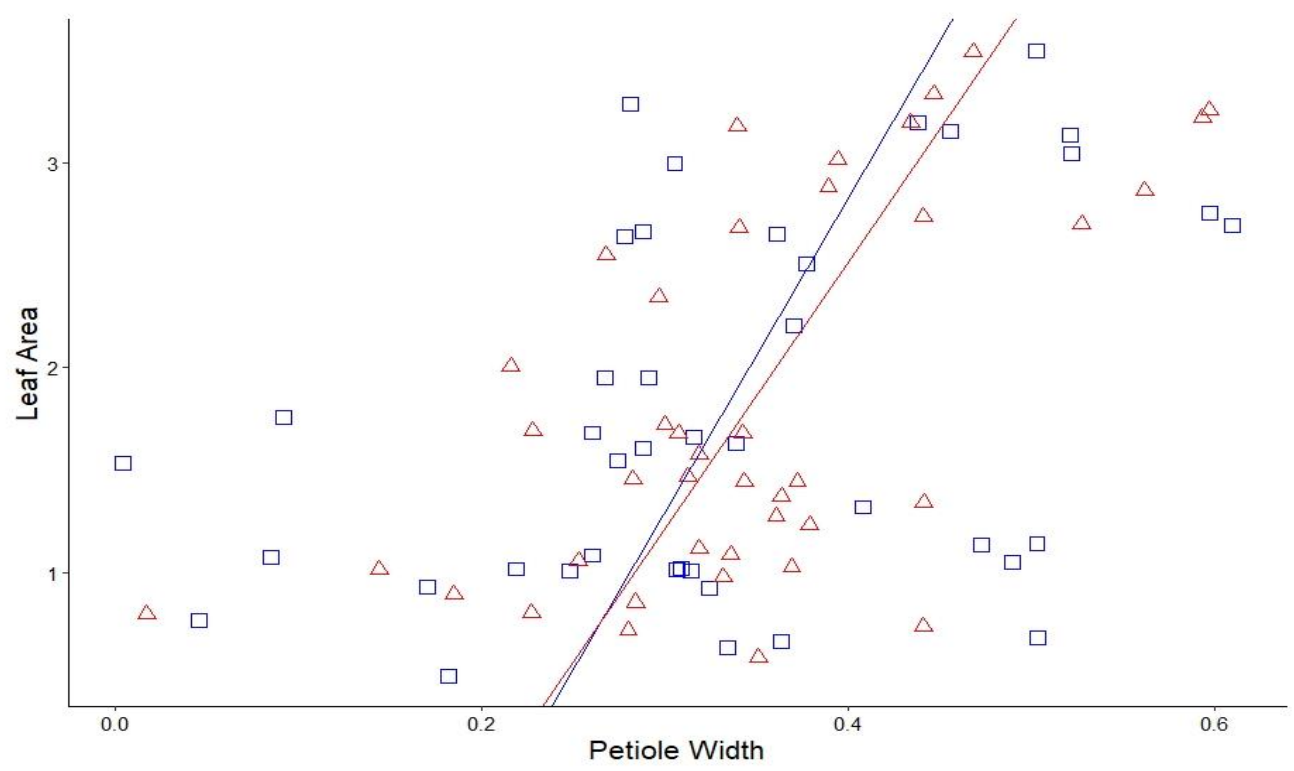

Figure 2.3 Petiole width against leaf area. Data points represent one Coprosma species. $\mathrm{X}=\log \mathrm{mm} . \mathrm{Y}=\log$ $\mathrm{mm}^{2}$. Males $(\square)$ and Females $(\Delta)$ plotted separately. The graph is fitted with a MA regression line for both males (solid blue) and females (solid red).

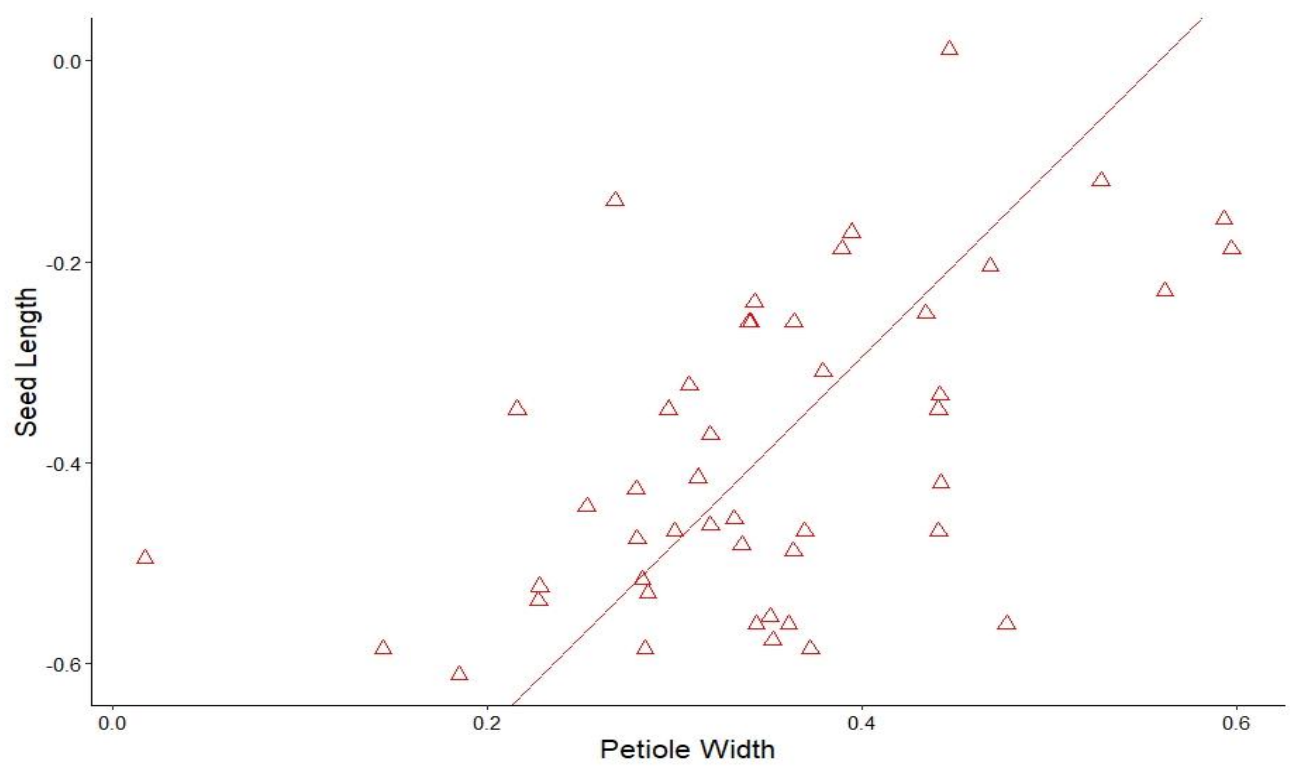

Figure 2.4 Petiole Width against seed length for female specimens $(\Delta)$. Data points represent one Coprosma species. $\mathrm{X}=\log \mathrm{mm} . \mathrm{Y}=\log \mathrm{mm}$. The graph is fitted with a MA regression line (solid red).

For the comparison of seed length with petiole width, 47 female specimens were utilised in the analysis, resulting in a correlation p-value of $<0.001$ (Table 2.2). The application of 
a MA regression gave a slope angle of 1.8580 with a 95\% CI of 1.1938 to 3.3489 and an intercept value of -1.0374 coupled with a $95 \%$ CI of -1.5577 to -0.8056 . Graphed data for female petiole width and seed length displays a positive correlation between both features (Figure 2.4).

Comparing seed length or leaf area for 47 female specimens gave a correlation $p$-value of $<0.001$. The graphed data displays a positive scaling relationship, with an MA regression slope angle of 6.7770 with a $95 \%$ CI of 5.6392 to 8.4716 , as well as an intercept value of 4.3655 and a $95 \%$ CI of 3.9229 to 5.0248 (Figure 2.5).

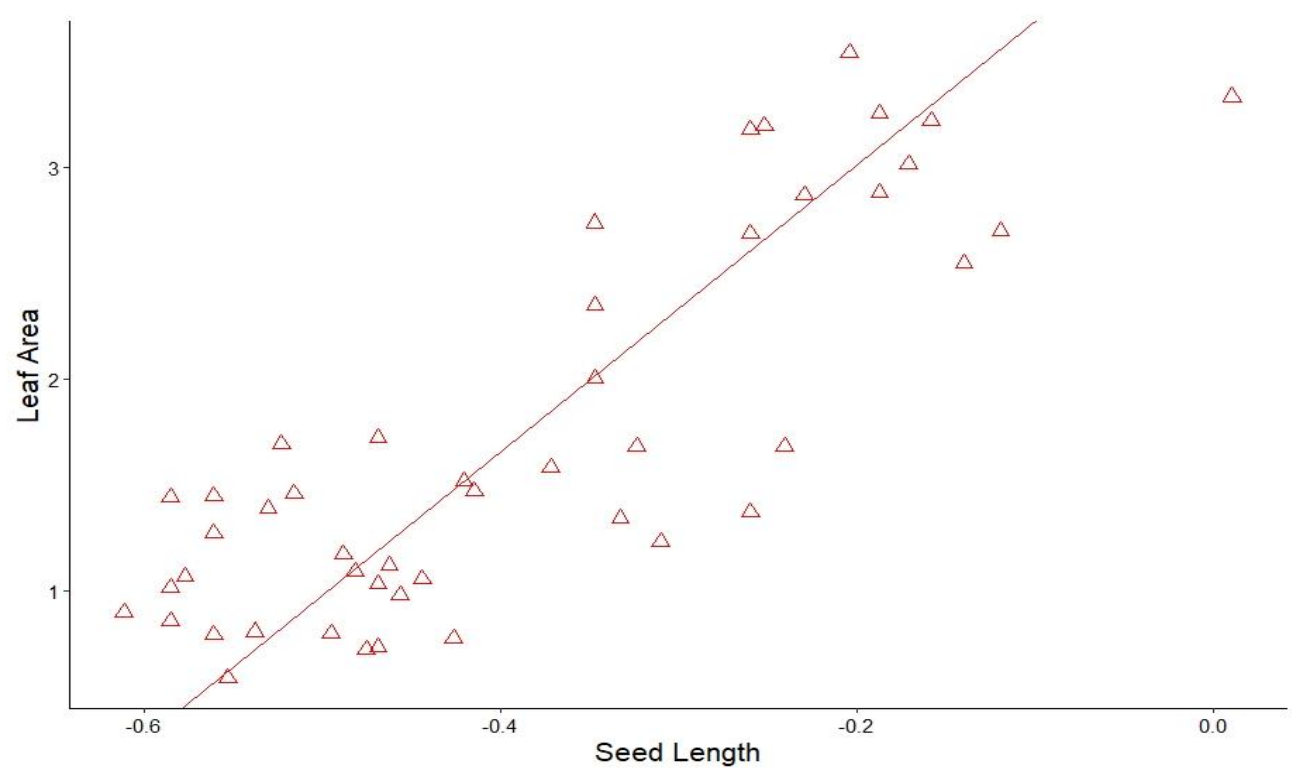

Figure 2.5 Seed Length against leaf area for female specimens $(\Delta)$. Data points represent one Coprosma species. $\mathrm{X}=\log \mathrm{mm} . \mathrm{Y}=\log \mathrm{mm}^{2}$. The graph is fitted with a MA regression line (solid red).

To explore the differences between males and females, male leaf area and female leaf area were compared, resulting in a correlation p-value of $<0.001$, with a slope angle of 1.0058 within a $95 \%$ CI of 0.9021 to 1.1215 , and an intercept of 0.0337 with a $95 \%$ CI of -0.1716 to 0.2177 .

(2) Are there significant scaling relationships between floral features of males and females?

This analysis excluded anther measurements, due to not having pollen size data. The size of the pollen granules is a determinant in the relevance of anther length and width. An 
anther with a larger volume may not necessarily carry larger pollen, as pollen size likely shows variation between species. A total of 41 within-species male and female pairs were compared within the analysis exploring the similarities and differences between the lengths of reproductive features. The correlation between seed length and stigma length gave a p-value of 0.001, whereas for filament length with seed length as well as filament length with stigma length both resulted in non-significant p-values (Table 2.3).

Table 2.3 Regression analysis between variables related to the relationship between sexes. Correlations were tested for significance with the cor.test function using a Pearson distribution.

\begin{tabular}{lllr}
$\boldsymbol{X}$ & $\boldsymbol{Y}$ & Test & p-value \\
\hline Seed Length & Stigma Length & cor & 0.001 \\
Filament Length & Seed Length & cor & 0.963 \\
Filament Length & Stigma Length & cor & 0.33
\end{tabular}

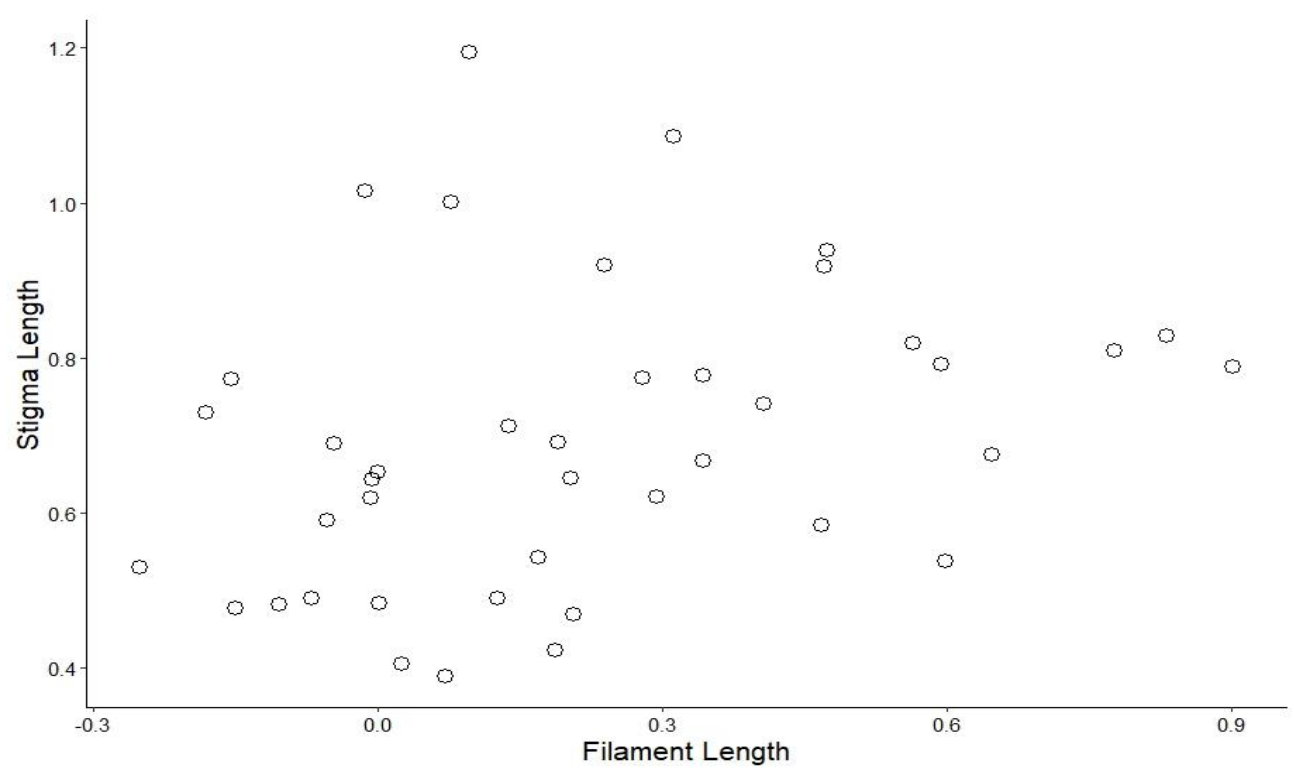

Figure 2.6 Filament Length against stigma length. Data points represent one Coprosma species. $X=\log$ $\mathrm{mm} . \mathrm{Y}=\log \mathrm{mm}$.

For filament and stigma length, application of the MA regression model gave a slope angle of 0.3248 with a $95 \%$ CI of 0.0130 to 0.7067 along with an intercept value of 0.6217 and a $95 \%$ CI of 0.5378 to 0.6902 (Figure 2.6). 
(3) Do the effects of elevation override Corner's Rule?

The elevation range of a Coprosma species was averaged for each of the study species. Each of the morphological features was measured against elevation to determine if altitude influences Corner's Rule for each of the species (Table 2.4).

Table 2.4 Regression analysis between variables related to the effect of elevation. Correlations were tested for significance with the $\mathrm{lm}$ function.

\begin{tabular}{l|llr}
$\boldsymbol{X}$ & $\boldsymbol{Y}$ & Test & p-value \\
\hline Elevation & Male Leaf Area & $\operatorname{lm}$ & 0.5 \\
Elevation & Male Petiole Width & $\operatorname{lm}$ & 0.65 \\
Elevation & Filament Length & $\operatorname{lm}$ & 0.36 \\
Elevation & Female Leaf Area & $\operatorname{lm}$ & 0.19 \\
Elevation & Female Petiole Width & $\operatorname{lm}$ & 0.42 \\
Elevation & Stigma Length & $\operatorname{lm}$ & 0.04 \\
Elevation & Seed Length & $\operatorname{lm}$ & 0.07 \\
Elevation & Maximum Plant Height & $\operatorname{lm}$ & 0.0008
\end{tabular}

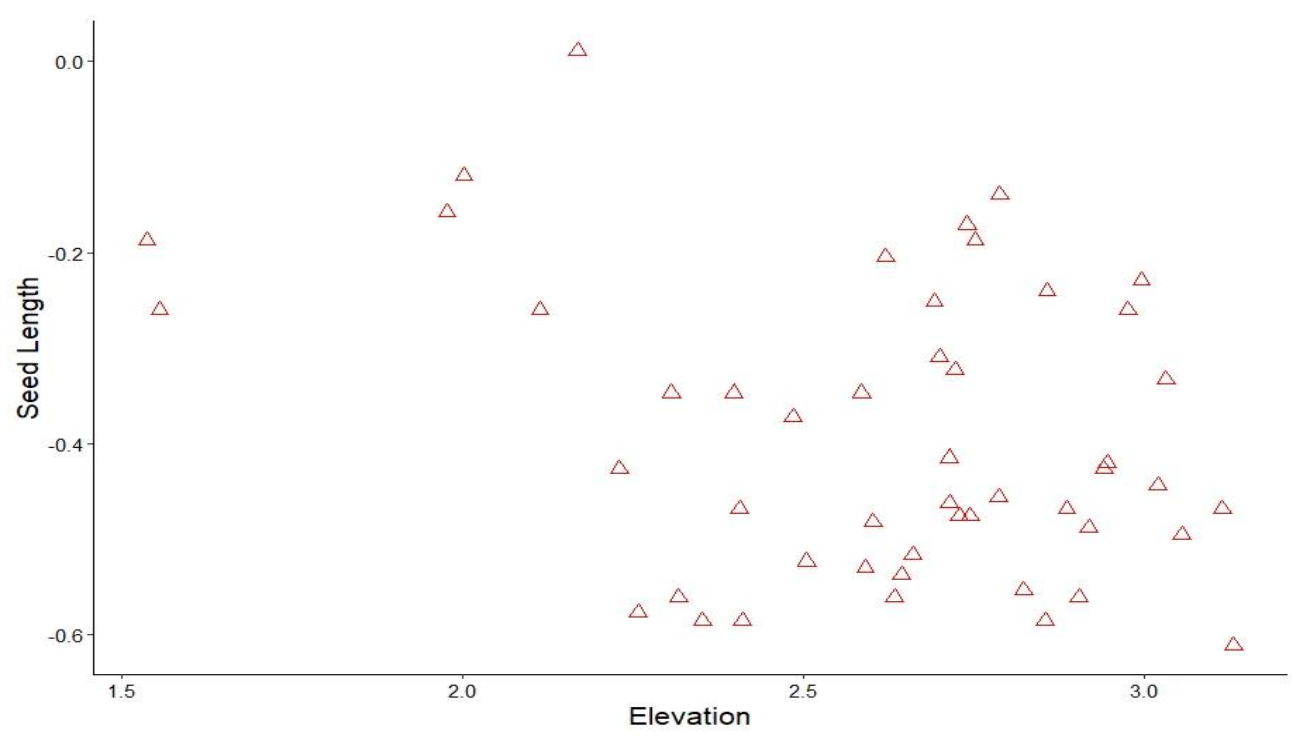

Figure 2.7 Elevation against seed length. Data points represent female specimens from one Coprosma species $(\Delta) . X=\log m . Y=\log m m$.

The effect of elevation on seed size for 49 female specimens within a simple linear regression model I yielded a p-value 0.07. Application of the MA regression model gave a 
slope angle of -0.1627 with a $95 \%$ CI of -0.3051 to -0.0264 and an intercept value of 0.0331 with a $95 \%$ CI of -0.3226 to 0.4049 (Figure 2.7).

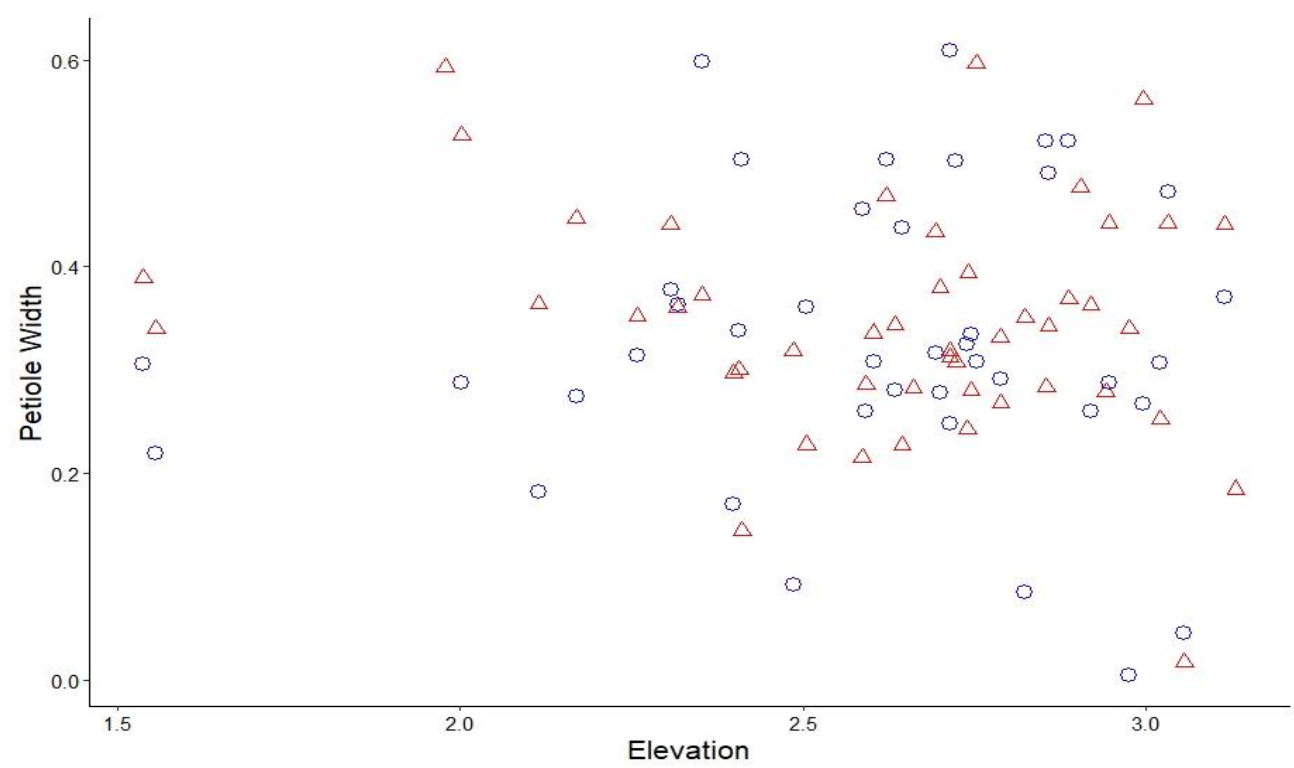

Figure 2.8 Elevation against petiole width. Data points represent males $(\square)$ and females $(\Delta)$ of one Coprosma species. $\mathrm{X}=\log m$. $\mathrm{Y}=\log \mathrm{mm}$.

A total of 48 male and 48 female petiole widths were plotted separately against elevation. A p-value of 0.65 resulted from Im modelling for male specimens and 0.43 for females. The MA regression model for male specimens gave a slope of 0.0156 with a $95 \%$ CI of 0.1254 to 0.1573 and an intercept value of 0.29 and a $95 \%$ CI of -0.0781 to 0.6565 . Similarly, females gave a slope angle of -0.0675 with a $95 \%$ CI of -0.1657 to 0.0295 and an intercept value of 0.5234 within a $95 \%$ CI of 0.2696 to 0.7805 (Figure 2.8). 


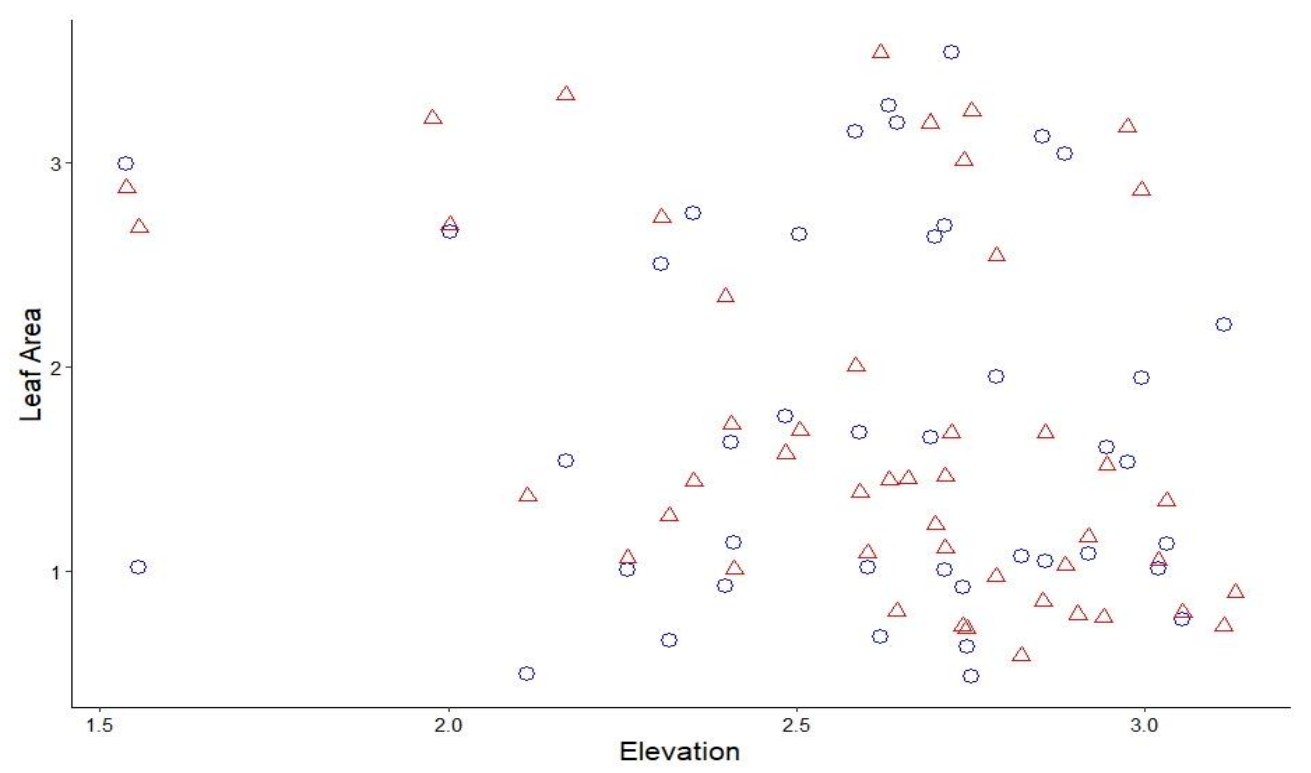

Figure 2.9 Elevation against petiole width. Data points represent females $(\Delta)$ and males $(\square)$ of one Coprosma species. $\mathrm{X}=\log m . \mathrm{Y}=\log \mathrm{mm}^{2}$.

Lastly, elevation measured against leaf area for 48 male and 48 female specimens gave a Im p-value of 0.5 and 0.19 , respectively. The slope angle for males was -5.2435 with a $95 \%$ CI of -17.8758 to -3.0074 along with an intercept value of 15.3653 within a $95 \%$ confidence interval of 9.5563 to 48.1815 . Females also gave similar values with a slope angle of -5.0351 with a $95 \%$ CI of -13.5903 to -3.0312 and an intercept value of 14.8917 within a $95 \%$ CI of 9.6449 to 37.2912 (Figure 2.9).

\subsection{Discussion}

For the Coprosma genus, allometric scaling of morphological features are abiding of Corner's Rule. Male and female petiole widths correlate positively with leaf area $(p=0.01$, $\mathrm{p}=<0.001$ respectively) which indicates that an increased leaf size yields a thicker petiole. The application of the MA regression model confirms non-isometric scaling in male specimens within the 50 sampled species (male slope $=15.3008,95 \% \mathrm{CI}=8.8625$, 55.0408), which is consistent with female specimens that display allometric scaling in petiole width and leaf area (slope $=12.9944,95 \%$ CI $=9.079,22.7603$ ). Intercept values for both male and females also show allometry, with rates of growth between leaf and petiole showing variance (male intercept $=-3.2917,95 \%$ CI $=-16.4498,-1.16$; female intercept $=-2.68,95 \% \mathrm{CI}=-6.0658,-1.3266)$. 
Similarly, seed length strongly correlates positively with petiole width $(\mathrm{p}=<0.001)$, indicating that the load of seed size requires sufficient support structures. The MA regression confirms a positive scaling relationship with an increase in seed length resulting in an increased petiole width, however, due to a non-isometric positive slope, the ratio of seed length to petiole width increases for larger plants (slope $=1.8580,95 \%$ $\mathrm{CI}=1.1938,3.3489$ ). This indicates that the petiole's width increases at a lesser rate than seed length as a plant gets bigger, further confirmed by allometry in the intercept (intercept $=-1.0374,95 \% \mathrm{CI}=-1.5577,-0.8056$ ).

Furthermore, seed length and leaf area were shown to strongly correlate $(\mathrm{p}=<0.001)$. The slope of the MA regression model within this analysis displayed a positive allometric relationship (slope $=6.777,95 \% \mathrm{CI}=5.6392,8.4716$ ) as well as a non-isometric intercept $(4.3655,95 \%$ CI $=3.9229,5.2048)$. However, mechanistically the length of a seed does not have direct influence or reliance on the size of a leaf. It is likely that this is an indirect association due to the strong scaling relationships between petiole width and leaf area, as well as petiole width and seed length. Yet seed size correlates strongly with seedling size, where a larger seedling size produces larger adult leaves (Cornelissen, 1999).

Male leaf area and female leaf area were shown to have a strong positive scaling relationship ( $\mathrm{p}=<0.001$ ). Differences between the leaf area are negligible as both male and female leaves show isometry in both slope and intercept (slope $=1.0058,95 \% \mathrm{CI}=$ $0.9021,1.1215$ : intercept $=0.0037,95 \%$ CI $=-0.1716,0.2177)$. The implication of this finding is that Corner's Rule is likely applicable to both sexes equally, with the triangular allometric scaling of petiole, seed, and leaf.

These results are consistent with the literature that describe an increased petiole or stem diameter with an increase in leaf area (Ackerly \& Donoghue, 1998; Cornelissen, 1999; White, 1983). However, recent research confirms Corner's Rule for non-divaricate plants yet contrarily concluded no correlation between leaf area and twig diameter in many New Zealand divaricate species, which may conflict with these results as the study species include divaricates (Maurin \& Lusk, 2020).

The differences between reproductive features within the Coprosma genus showed variation. Seed length and stigma length displayed a strong correlation, indicating that the larger the stigma, the larger the produced seed $(p=0.001)$. However, when 
investigating if male and female reproductive features scale isometrically or allometrically with one another the results show no correlations between male and female features. Filament length and seed length displayed this lack of correlation $(\mathrm{p}=$ 0.9633) as with filament length and stigma length $(\mathrm{p}=0.33)$. The implication of these findings suggest that the lengths of structural reproductive features show no scaling relationships between the sexes, as filament length is not determined by the length of the stigma or vice versa. However, literature suggests that pollen size correlates strongly with stigma length (Williams \& Rouse, 1990). An increased pollen size enables a longer pollen tubule used during pollination. If the pollen tubule cannot reach the ovule through the stigma, pollination does not occur. It is evident that filament length is likely determined by other ecological processes.

As shown in prior results, Corner's Rule is applicable within study species for allometric scaling of petiole, leaf, and seed. Elevation shows a strong negative correlation with plant height ( $p=0.0008)$, that when extrapolated may be hypothesised to result in a reduced leaf and petiole due to the association between plant size and feature size. However, the effects of elevation displayed no correlations with seed, leaf, and petiole. Elevation and seed length yielded non-significance in correlation $(p=0.07)$, indicating that seed size is not influenced by altitude. This is consistent with leaf size for both male and females that also showed no correlation $(0.5,0.19$ respectively). Furthermore, petiole widths for both males and females showed no correlation with elevation ( $p=0.65,0.42$ respectively).

A higher altitude is associated with an increase in the extremes of environmental conditions (Tranquillini, 1964). Alpine plants are often exposed to colder weather and harsher winds; a plant with increased leaf surface area would likely increase the risk of structural damage. However, these results indicate that Corner's Rule is not overridden by elevation for the Coprosma genus. If it were, the observed results would display correlations between elevation and feature size. Yet, this also may be due to lower altitude Coprosma plants not necessarily having larger leaf sizes compared to higher altitude, as many have small and thin leaves and petioles scaled to their size.

These results contrast with studies that display a decrease in leaf area with an increase in altitude for many species (Milla et al., 2011, Pan et al., 2013). It is evident that leaf, petiole, and seed size at high altitude is influenced by a wider range of extremes in 
environmental influences than just elevation. Wind exposure, sun radiation, soil and air temperatures, humidity, precipitation, frost and snow all influence plant morphology across an elevational gradient (Tranquillini, 1964). For example, Hovenden \& Vander Schoor (2006) found that altitude has little impact on leaf area when the plant is exposed to full sunlight, as opposed to shaded leaves that are more affected. Lower altitude plants require the ability to adapt to a wide range of light environments, resulting in higher morphological plasticity, whereas high altitude is often exposed to a uniform light environment and show less variation in leaf area (Hovenden \& Vander Schoor, 2006).

This chapter explored three research questions to investigate the allometric scaling of features within herbarium specimens of the Coprosma genus: (1) Does Coprosma morphology scale allometrically as described by Corner's Rule? (2) Are there significant scaling relationships between floral features of males and females? (3) Do the effects of elevation override Corner's Rule? The results accept the applicability of Corner's Rule on the studied herbarium specimens, with significant allometric scaling relationships in petiole, seed, and leaf. However, no scaling relationships were observed between male and female reproductive structures. It is also evident that elevation does not override Corner's Rule for these species, with no evidence of a negative correlation between feature size and increasing elevation.

The limitations of this study primarily involve the sampling of herbarium specimens. The shrinking of the clippings due to drying during the preservation process influences lengths and sizes of features, as well as the filaments and stigma being coiled or curved or even broken due to their fragility. Further work is required to investigate these scaling relationships more accurately with the use of live plants. For the differences between reproductive structures, research involving pollen size and its scaling relationships with anther size and volume, along with filament length and stigma length would provide further insight into the reproductive features that have a more direct interaction during pollination, i.e., pollen size and stigma length. For the test of elevation, replicate studies for Corner's Rule would be suggested to examine the degree of allometric scaling in seed, leaf, and petiole for plants of low altitude compared to high altitude. 


\subsection{References}

Ackerly, D. D., \& Donoghue, M. J. (1998). Leaf size, sapling allometry, and Corner's rules: phylogeny and correlated evolution in maples (Acer). The American Naturalist, 152(6), 767-791.

Bond, W. J., \& Midgley, J. (1988). Allometry and sexual differences in leaf size. The American Naturalist, 131(6), 901-910.

Cornelissen, J. H. C. (1999). A triangular relationship between leaf size and seed size among woody species: Allometry, Ontogeny, Ecology and Taxonomy. Oecologia, 118(2), 248-255. JSTOR.

Corner, E. J. H. (1949). The durian theory or the origin of the modern tree. Annals of Botany, 13(52), 367-414.

Hovenden, M. J., \& Vander Schoor, J. K. (2004). Nature vs nurture in the leaf morphology of Southern beech, Nothofagus cunninghamii (Nothofagaceae). New Phytologist, 161(2), 585-594.

Hovenden, M. J., \& Vander Schoor, J. K. (2006). The response of leaf morphology to irradiance depends on altitude of origin in Nothofagus cunninghamii. New Phytologist, 169(2), 291-297.

Klumpers, S. G., Klinkhamer, P. G., \& Stang, M. (2017). Scaling relationships between flower size and nectar reward at the scale of single flowers, flower heads, individual plants, and patches among subalpine Asteraceae. Beyond random and forbidden interactions in plant-pollinator networks: how, 45.

Körner, C. (2007). The use of 'altitude' in ecological research. Trends in ecology \& evolution, 22(11), 569-574.

Lauri, P.-É. (2019). Corner's rules as a framework for plant morphology, architecture, and functioning - issues and steps forward. New Phytologist, 221(4), 1679-1684.

Maurin, K. J., \& Lusk, C. H. (2020). Do the New Zealand divaricates defy Corner's rules?.

Milla, R., \& Reich, P. B. (2011). Multi-trait interactions, not phylogeny, fine-tune leaf size reduction with increasing altitude. Annals of Botany, 107(3), 455-465. 
Pan, S., Liu, C., Zhang, W., Xu, S., Wang, N., Li, Y., ... \& Wang, G. (2013). The scaling relationships between leaf mass and leaf area of vascular plant species change with altitude. PloS one, 8(10), e76872.

Tranquillini, W. (1964). The physiology of plants at high altitudes. Annual Review of Plant Physiology, 15(1), 345-362.

White, P. S. (1983). Evidence that temperate east North American evergreen woody plants follow Corner's rules. New Phytologist, 95(1), 139-145. 


\subsection{Appendices}

\subsubsection{Male Herbarium Data}

\begin{tabular}{|c|c|c|c|}
\hline Species & Petiole & Leaf & Filament \\
\hline Coprosma acerosa A.Cunn. & 2.1600 & 4.3250 & 1.4775 \\
\hline Coprosma acutifolia Hook.f. & 2.0200 & 989.0852 & 3.6728 \\
\hline Coprosma arborea Kirk & 2.3850 & 321.7111 & 4.4450 \\
\hline Coprosma areolata Cheeseman & 2.1800 & 42.6902 & 1.6100 \\
\hline Coprosma atropurpurea & 1.1100 & 5.8756 & 5.9821 \\
\hline Coprosma chathamica & 1.9400 & 459.3412 & 3.9350 \\
\hline \multicolumn{4}{|l|}{ Coprosma cheesemanii } \\
\hline Coprosma ciliata & 2.0350 & 10.4417 & 1.1779 \\
\hline Coprosma colensoi & 3.0900 & 11.2349 & 1.1960 \\
\hline Coprosma crassifolia & 1.2350 & 57.2165 & 0.6591 \\
\hline Coprosma crenulata & 2.9700 & 13.5990 & 0.9705 \\
\hline Coprosma cuneata & 1.7700 & 10.1769 & 2.9400 \\
\hline \multicolumn{4}{|l|}{ Coprosma decurva } \\
\hline Coprosma depressa & 2.0250 & 10.4059 & 0.9824 \\
\hline \multicolumn{4}{|l|}{ Coprosma distantia } \\
\hline Coprosma dondonaefolia & 3.3250 & 1106.7394 & 1.7354 \\
\hline Coprosma dumosa & 2.1100 & 8.3820 & 0.7871 \\
\hline \multicolumn{4}{|l|}{ Coprosma elatirioides } \\
\hline Coprosma feotidissima & 2.3450 & 160.3574 & 2.9810 \\
\hline Coprosma fowerakeri & 3.1900 & 4.8250 & 1.5375 \\
\hline Coprosma grandifolia & 3.1800 & 3494.0531 & 2.2054 \\
\hline Coprosma intertexta & 2.0350 & 3.0632 & 0.5970 \\
\hline Coprosma linariifolia & 1.8800 & 35.0199 & 1.9679 \\
\hline Coprosma lucida & 3.3200 & 1350.2599 & 2.0539 \\
\hline Coprosma macrocarpa & 2.7400 & 1562.2144 & 2.5515 \\
\hline Coprosma microcarpa & 2.0600 & 10.2492 & 1.0013 \\
\hline \multirow{2}{*}{\multicolumn{4}{|c|}{ Coprosma parviflora }} \\
\hline & & & \\
\hline Coprosma pedicellata & 3.1850 & 13.9214 & 0.7085 \\
\hline Coprosma perpusilla ssp. Perpusilla & 1.6550 & 10.4257 & 6.7864 \\
\hline Coprosma perpusilla ssp. Subantarctica & 1.2150 & 11.9189 & 7.9767 \\
\hline Coprosma petiolata & 1.8967 & 433.5898 & 0.9847 \\
\hline Coprosma petriei & 1.5200 & 3.1444 & 3.9730 \\
\hline Coprosma propinqua & 1.8200 & 12.1430 & 0.8525 \\
\hline Coprosma propinqua var. martinii & 1.9400 & 40.4544 & 1.0040 \\
\hline \multicolumn{4}{|l|}{ Coprosma pseudociliata } \\
\hline \multicolumn{4}{|l|}{ Coprosma pseudocuneata } \\
\hline Coprosma repens & 4.0700 & 494.9301 & 1.3760 \\
\hline Coprosma rhamnoides & 2.0700 & 45.5515 & 0.7000 \\
\hline Coprosma rigida & 2.2950 & 449.2923 & 1.5516 \\
\hline Coprosma robusta & 2.8550 & 1422.3305 & 2.2049 \\
\hline Coprosma rotundifolia & 1.9550 & 89.4554 & 1.0613 \\
\hline Coprosma rubra & 1.8500 & 88.6766 & 1.5963 \\
\hline Coprosma rugosa & 1.4800 & 8.4819 & 1.3380 \\
\hline Coprosma serrulata & 3.9600 & 568.0155 & 1.2488 \\
\hline Coprosma spathulata & 1.0100 & 34.1793 & 1.9000 \\
\hline Coprosma tenuicaulis & 1.8200 & 48.0549 & 0.8825 \\
\hline Coprosma tenuifolia & 1.9100 & 1913.1741 & 2.9617 \\
\hline \multicolumn{4}{|l|}{ Coprosma virescens } \\
\hline Coprosma wallii & 2.5600 & 20.8787 & 0.5613 \\
\hline
\end{tabular}




\subsubsection{Female Herbarium Data}

\begin{tabular}{|c|c|c|c|}
\hline Species & Petiole & Leaf & Stigma \\
\hline Coprosma acerosa A.Cunn. & 1.9050 & 5.2671 & 3.4856 \\
\hline Coprosma acutifolia Hook.f. & 2.4500 & 754.7560 & 6.5837 \\
\hline Coprosma arborea Kirk & 2.7600 & 543.4254 & 4.7330 \\
\hline Coprosma areolata Cheeseman & 1.9950 & 52.4173 & 2.9478 \\
\hline Coprosma atropurpurea & 1.0400 & 6.2869 & 6.4517 \\
\hline Coprosma chathamica & 3.3700 & 498.8798 & 6.1969 \\
\hline Coprosma cheesemanii & 1.9025 & 5.9723 & 5.9578 \\
\hline Coprosma ciliata & 2.1667 & 12.2639 & 2.4475 \\
\hline Coprosma colensoi & 2.2000 & 47.8137 & 10.0140 \\
\hline Coprosma crassifolia & 2.0833 & 37.9150 & 5.3585 \\
\hline Coprosma crenulata & 2.7633 & 22.0570 & 10.3688 \\
\hline Coprosma cuneata & 2.0833 & 13.1066 & 3.8363 \\
\hline Coprosma decurva & 3.0000 & 6.1870 & 2.4042 \\
\hline Coprosma depressa & 1.7900 & 11.4201 & 4.1585 \\
\hline \multicolumn{4}{|l|}{ Coprosma distantia } \\
\hline Coprosma dondonaefolia & 2.4800 & 1030.0903 & 8.3100 \\
\hline Coprosma dumosa & 2.3400 & 10.7266 & 3.0372 \\
\hline Coprosma elatirioides & 1.7500 & 5.4264 & 2.7288 \\
\hline Coprosma feotidissima & 1.8533 & 352.3781 & 8.6869 \\
\hline Coprosma fowerakeri & 2.7600 & 5.4406 & 2.6460 \\
\hline Coprosma grandifolia & 2.9400 & 3448.8142 & 4.6483 \\
\hline \multicolumn{4}{|l|}{ Coprosma intertexta } \\
\hline Coprosma linariifolia & 2.0300 & 47.6911 & 4.1769 \\
\hline Coprosma lucida & 3.9550 & 1790.3888 & 12.1804 \\
\hline Coprosma macrocarpa & 2.7967 & 2144.3909 & 5.4934 \\
\hline Coprosma microcarpa & 1.9233 & 7.1792 & 4.4990 \\
\hline Coprosma obconica & 1.6867 & 6.4137 & 4.8919 \\
\hline Coprosma parviflora & 2.2500 & 11.6926 & 2.4106 \\
\hline Coprosma pedicellata & 2.2950 & 18.7863 & 2.9991 \\
\hline Coprosma perpusilla ssp. Perpusilla & 1.5300 & 7.9039 & 6.7476 \\
\hline Coprosma perpusilla ssp. Subantarctica & 1.3933 & 10.3291 & 6.1462 \\
\hline Coprosma petiolata & 2.1900 & 482.8521 & 4.3963 \\
\hline Coprosma petriei & 2.2433 & 3.8766 & 3.4494 \\
\hline Coprosma propinqua & 2.3933 & 17.0706 & 3.0933 \\
\hline Coprosma propinqua var. martinii & 2.3100 & 23.5446 & 3.0420 \\
\hline Coprosma pseudociliata & 2.3075 & 14.8662 & 3.0086 \\
\hline Coprosma pseudocuneata & 2.7675 & 33.0552 & 7.2940 \\
\hline Coprosma repens & 3.9200 & 1658.0852 & 5.1590 \\
\hline Coprosma rhamnoides & 1.9167 & 28.5795 & 5.9258 \\
\hline Coprosma rigida & 2.0533 & 29.4656 & 4.9113 \\
\hline Coprosma robusta & 2.7167 & 1570.7515 & 5.9884 \\
\hline Coprosma rotundifolia & 1.6900 & 48.9949 & 2.5417 \\
\hline Coprosma rubra & 1.6433 & 100.8181 & 4.4089 \\
\hline Coprosma rugosa & 2.1467 & 9.5021 & 3.0938 \\
\hline Coprosma serrulata & 3.6450 & 732.0085 & 15.6700 \\
\hline Coprosma spathulata & 1.9800 & 221.3176 & 5.9483 \\
\hline Coprosma tenuicaulis & 2.3567 & 27.6865 & 3.8984 \\
\hline Coprosma tenuifolia & 2.1850 & 1500.2520 & 8.2730 \\
\hline Coprosma virescens & 1.9300 & 24.3461 & 2.7798 \\
\hline Coprosma wallii & 2.2050 & 27.9350 & 3.3885 \\
\hline
\end{tabular}




\subsubsection{Landcare Research Data}

\begin{tabular}{|c|c|c|c|}
\hline Species & Seed & Plant Height & Elevation \\
\hline Coprosma acerosa A.Cunn. & 0.3350 & 20 & 555 \\
\hline Coprosma acutifolia Hook.f. & 0.6500 & 1000 & 35 \\
\hline Coprosma arborea Kirk & 0.4500 & 1000 & 203 \\
\hline Coprosma areolata Cheeseman & 0.3400 & 600 & 255 \\
\hline Coprosma atropurpurea & 0.3200 & 5 & 1135 \\
\hline Coprosma chathamica & 0.7600 & 1500 & 101 \\
\hline Coprosma cheesemanii & 0.3750 & 100 & 873 \\
\hline Coprosma ciliata & 0.3300 & 700 & 400 \\
\hline Coprosma colensoi & 0.5750 & 200 & 720 \\
\hline Coprosma crassifolia & 0.4250 & 400 & 306 \\
\hline Coprosma crenulata & 0.4650 & 10 & 1075 \\
\hline Coprosma cuneata & 0.3450 & 100 & 518 \\
\hline Coprosma decurva & 0.2750 & 300 & 802 \\
\hline Coprosma depressa & 0.3600 & 150 & 1048 \\
\hline Coprosma distantia & 0.3750 & 5 & 170 \\
\hline Coprosma dondonaefolia & 0.6750 & 300 & 550 \\
\hline Coprosma dumosa & 0.3400 & 700 & 770 \\
\hline Coprosma elatirioides & & 100 & 548 \\
\hline Coprosma feotidissima & 0.7250 & 600 & 613 \\
\hline Coprosma fowerakeri & 0.3400 & 60 & 1300 \\
\hline Coprosma grandifolia & 0.6250 & 600 & 418 \\
\hline Coprosma intertexta & 0.3350 & 200 & 535 \\
\hline Coprosma linariifolia & 0.4750 & 800 & 528 \\
\hline Coprosma lucida & 0.6500 & 300 & 565 \\
\hline Coprosma macrocarpa & 1.0250 & 360 & 148 \\
\hline Coprosma microcarpa & 0.2600 & 400 & 715 \\
\hline Coprosma obconica & 0.2900 & 400 & 441 \\
\hline Coprosma parviflora & 0.2650 & 500 & 181 \\
\hline Coprosma pedicellata & 0.2750 & 900 & 208 \\
\hline Coprosma perpusilla ssp. Perpusilla & 0.2450 & 5 & 1350 \\
\hline Coprosma perpusilla ssp. Subantarctica & 0.2600 & 5 & 258 \\
\hline Coprosma petiolata & 0.5500 & 50 & 36 \\
\hline Coprosma petriei & 0.2800 & 5 & 665 \\
\hline Coprosma propinqua & 0.4900 & 500 & 501 \\
\hline Coprosma propinqua var. martinii & 0.5500 & 200 & 130 \\
\hline Coprosma pseudociliata & 0.3250 & 300 & 830 \\
\hline Coprosma pseudocuneata & 0.3800 & 300 & 883 \\
\hline Coprosma repens & 0.6950 & 800 & 95 \\
\hline Coprosma rhamnoides & 0.3050 & 200 & 458 \\
\hline Coprosma rigida & 0.3850 & 200 & 518 \\
\hline Coprosma robusta & 0.5600 & 600 & 493 \\
\hline Coprosma rotundifolia & 0.3000 & 300 & 320 \\
\hline Coprosma rubra & 0.4500 & 400 & 385 \\
\hline Coprosma rugosa & 0.3500 & 300 & 612 \\
\hline Coprosma serrulata & 0.5900 & 100 & 990 \\
\hline Coprosma spathulata & 0.4500 & 200 & 250 \\
\hline Coprosma tenuicaulis & 0.2600 & 300 & 225 \\
\hline Coprosma tenuifolia & 0.5500 & 500 & 945 \\
\hline Coprosma virescens & 0.2950 & 600 & 390 \\
\hline Coprosma wallii & 0.2750 & 500 & 430 \\
\hline
\end{tabular}




\section{The Allometry of Flightlessness in Island Birds}

Abstract Flight is the primary form of locomotion for many avian species and is enabled by allometric scaling of morphological features such as wingspan, flight muscle size, and bone tensile strength. Contrary to this, the evolution of flightlessness in birds displays a selection towards an increase in body size with a reduction in flight associated features. The aim of this chapter is to explore the Loss of Dispersibility hypothesis as a cause for flightlessness in island birds, with consideration of the Island Rule and the Size-Constraint hypothesis. With island species paired with closest mainland relatives, comparative analyses were conducted comparing the change in wing loading ratios, wing lengths, and mass. With paired t-tests and Major Axis linear regression modelling, the hypotheses of isometric or allometric scaling in each of the features were tested. An increase in wing-loading ratio was apparent for many island species, as well as an increase in both mass and wing length. However, the rate of increase between mass and wing length is disproportionate, with mass increasing at a greater rate than wing length. These trends reject the Loss of Dispersibility hypothesis in support of the Size-Constraint hypothesis while providing little evidence for the Island Rule.

\subsection{Introduction}

As described by Charles Darwin in On the Origin of Species, evolutionary modification in both form and function is a product of natural selection, with change over evolutionary time defined as descent with modification (Darwin, 1859). From this, it could be extrapolated that morphology scaling allometrically would serve a distinct purpose to aid a species' survival. An example of evolutionary modification that has led to the success of an entire taxonomic Class and has captivated researchers for centuries is that of flight. Containing near 11,000 species, the Aves house a plethora of species that use flight as their primary form of locomotion, a unique ability only found within the two extant vertebrate groups of the birds and bats (BirdLife International, 2017). Avian species' reliance on flight varies, from the burst take-offs and sprints to the near permanent soarers in the sky. Flight is theorised to have a suite of associated benefits unattainable by land bound species, from an effective means of predator avoidance to its use in accessing or capturing food-utilising their habitat in a third dimension, rather than being restricted to a $2 \mathrm{D}$ plane. 
To enable flight, isometric or allometric scaling relationships within a bird's morphology are evident in a range of features. Such examples include muscles associated with flight being large enough to beat wings for lift to be achieved, the supporting skeleton with enough tensile strength to withstand the forces of flight, or even the dimensions of flight feathers large enough to push against and capture air-all of which scale allometrically with mass (Sullivan, 2019). A common measure of a bird's flight efficiency can be indicated by wing loading ratios. With application of aerodynamical flight theory, selection should favour a reduced body size with an increased wingspan (Hendenström \& Møller, 1992). A high wing loading ratio indicates a poorer flyer, with its wings lifting more mass per unit of wing area. For example, the high proportion of body fat stored during migration for many species is hypothesised to increase the risk of predation due to the decrease in its ability to escape predators with a wing loading ratio too high that it slows take-off time (Burns \& Ydenberg, 2002).

With many benefits of flight, curiosities surround those species that selection has favoured and displayed a trend towards, and ultimately evolved, flightlessness. This evolutionary change in historically capable flyers has evolved repeatedly in a variety of species, throughout locations isolated and exclusive of one another (Campagna et al., 2019). The Rallidae family has many examples of this parallel evolution, with 31 of the 150 known species within this group evolving flightlessness (Kirchman, 2012). Genetic distances between flightless rails and their volant relatives in research assessing $12 \mathrm{~S}$ sequence distances discovered that flightless species ranged between $0.3 \%$ to $7.6 \%$ in deviance from their counterparts, indicating that flightlessness can evolve in rapid succession (Trewick, 1997). Practical examples of this include such places as the Aldabra atoll in the Seychelles that experienced an inundation event from a sea-level rise during the upper Pleistocene, that cleared the atoll of terrestrial life (Hume \& Martill, 2019). Fossil evidence suggests that two species of Dryolimnas colonized the area and evolved flightlessness on two separate occasions, one before the inundation event and one after (Hume \& Martill, 2019). These species likely would have dispersed and colonised from Madagascar and both displayed this rapidity in evolving flightlessness (Hume \& Martill, 2019).

Causality behind the inability to fly evolving in parallel on numerous occasions is linked to the consistent trends in morphology across flightless species. The anatomy of a 
flightless bird is associated with a larger body size, smaller wings, and less flight muscle mass than those of capable flyers (Guillemette \& Ouellet, 2005). If a species over time evolves towards larger body size, the energy required to fly versus the energy available may increase to excess, rendering the bird incapable of taking off-more so sustaining the action of flight (Guillemette \& Ouellet, 2005). A proposed $2.5 \mathrm{~g}$ of body mass per $1 \mathrm{~cm}^{2}$ of wing area was suggested to be the maximum threshold for wing loading, with anything above resulting in flightlessness (Meunier, 1951). The likelihood of flightlessness evolving was also proposed to often occur in species that already had a large body mass with shorter wings, indicating that the energetic cost of flight was already high (McCall et al., 1998).

In a contrasting example, flightlessness in insects has been linked to occur in a species that exist in historically stable habitats (Wagner \& Liebherr, 1992; Zera et al., 1997). For these species there is also a link to an increase in reproductive potential as energy conserved is reinvested into reproductive processes, yielding more offspring (Wagner \& Liebherr, 1992; Zera et al., 1997). In scarabaeoids it is often found that only the females are flightless, as the energetic trade-off of flight against reproduction is large, and in species where neither sex can fly, it is thought to be because the species exists in microhabitats or densely populated same-species areas where finding a mate is highly probable (Scholtz, 2015).

With similarities to insects, the hypothesis of energy conservation is a frequently proposed answer to this evolutionary trend, as flight via flapping is one of the most metabolically expensive activities for birds (Winter \& Helversen, 1998). Brian McNab (1994) found basal metabolic rates in flightless kiwi, rails, and some ducks were lower than in birds that were flighted and had a smaller pectoral muscle mass. A lower metabolic rate translates to lesser energy expenditure, which results in a smaller requirement of energy gain via food consumption as fuel (McNab, 1994). Referring to the rails, flightless populations in areas with limited resources often show improved persistence, as the preservation of energy that would be spent on flight allows the existence of the populations on islands (McNab, 1994).

Flightlessness is not considered a product of de-evolution. An investigation on the brain size of flightless birds concluded that there were no correlations between flightlessness 
and small brains, indicating that the neurological requirements between flightless and volant species are not significantly different (Iwaniuk et al., 2006). Additionally, an increased likelihood of loss of flight was discovered to occur in lineages that experience simultaneous moult, as the birds were more prepared to adjust quickly to habitats that did not require flight, such as niches that exist on islands (Terrill, 2020).

Assessing the question as to why birds evolve flightlessness suggests that this adaptation would serve the purpose of increased fitness for species where flightlessness is favoured via natural selection. The streamer duck Tachyeres sp. for example has improved thermoregulation and diving ability due to shorter appendages and an increase in body size, as well as decreased risk of injury during displays of territoriality, where male ducks fight using spurs on their wings (Campagna et al., 2019).

The evolution of flightlessness has often occurred more frequently on islands. Insularity and fewer predatory species are associated with this change, indicating that both biogeography and lack of predation pressure result in the observed adaptation, driven by the need to conserve energy due to reduced habitat area and likely reduced abundance of food on islands compared to the mainland (Wright et al., 2016). Islands serve as a unique staging ground for evolutionary change due to the speciation rate hypothesis which suggests that as isolation increases gene flow decreases, which results in greater potential for local adaptation (Lester et al., 2007). Charles Darwin (1859) described the existence of flightless animals on insular islands with an analogy of two circumstances for sailors in a shipwreck, the first for sailors to be strong enough swimmers to reach the shore and the second for poor swimmers to cling to the wreck (Burns, 2018). Darwin's Loss of Dispersibility hypothesis describes the colonisation of islands by good dispersers and through time evolve poorer dispersal powers to avoid the risk of mortality due to being blown out to sea (Burns, 2018). Today, the evolution of flightlessness for a species in insularity could be described by three hypotheses: The Loss of Dispersibility hypothesis, the Size-Constraint hypothesis, and the Island Rule.

\subsubsection{The Loss of Dispersibility Hypothesis}

An observation that led to the Loss of Dispersibility hypothesis was first described in $O n$ the Origin of Species with observations made on the inhabitants of insular oceanic islands (Darwin, 1859). The primary observation Darwin made was that the adaptive trait of 
hooks on seeds would serve little purpose on insular islands in the absence of mammals. Darwin highlighted that the hook would become redundant in which he likened to 'the shrivelled wings under the soldered wing covers of many insular beetles' (Darwin, 1859, pp. 467). It is within this comment that Darwin first hinted at the redundancy of flight appendages on species that exist in insularity. Darwin further suggested that the loss of flight would increase survivability due to individuals not being blown out to sea (Darwin, 1856). He proposed that selection had favoured a decrease in wing length of these insular beetles, resulting in secondary flightlessness for the species. The observed changes within insularity, such as the loss of hooks, or the reduction in wing length, ultimately lead to insular species endemism with reduced dispersal ability comparative to their mainland counterparts.

However, in 1948 Elwood Zimmerman argued that beetles that inhabit the understory, primarily in leaf litter where wind likely was not a factor, lost their ability to fly due to its high energy cost and that it was no longer necessary for feeding or evading predators (Zimmerman \& Liebherr, 1948). The loss of dispersibility in plants was confirmed by Sherwin Carlquist in 1966(b), who found numerous examples of lost dispersal ability in Hawaiian plants such as the species of Bidens that had lost its awnings and hairs that were likely an adaptive trait to catch on to feathers or fur for dispersal. This was further confirmed in 1996 with both the Hypochaeris and Lactuca species that had a notable reduction in its pappus on fruiting bodies in only a few generations (Cody \& Overton, 1996).

The loss of dispersibility hypothesis has typically been applied to a reduction in functional appendages that aid the dispersal of a seed, as the components of a fruit are typically designed to contain seeds and morphological structures to enable their dispersal (Burns, 2019). However, allometric scaling of dispersal aids display covariance with the size of the seed, as a larger seed size requires larger dispersal mechanisms (Burns, 2019). The loss of dispersibility may likely be associated with the increase in seed size as opposed to a reduction in size of the dispersal aid (Burns, 2019).

\subsubsection{The Size-Constraint Hypothesis}

Contrary to the Loss of Dispersibility hypothesis, the Size-Constraint hypothesis describes the reduced dispersal ability in insular plant species being brought about by 
not a reduction in dispersal aids, but an increase in seed size (Burns, 2019). Carlquist (1966a) theorized that the increased size of seeds in insularity is positively favoured for via natural selection, as well as the decrease in dispersal aid size relative to the seed is a product of retention due to its negligible negative influence on selection (Burns, 2019).

Research by Patrick Kavanagh and Kevin Burns (2014) confirmed this by finding that seed sizes of insular plants are consistently larger than that of their closest mainland relatives, indicating that selection does in fact favour for increased seed size on islands. In relation to dispersibility, implications of this suggest that plants in insular island habitats require a lesser capacity for dispersal compared to their mainland relatives. It is hypothesised that this could be due selection favouring reduced mortality by a reduction of dispersal distance to reduce the potential for seeds to be distributed seeds to sea, as well as promote a competitive advantage for seedlings due to an increase in the nutrient reserves of a larger seed (Kavanagh \& Burns, 2014). Applicability of this hypothesis to animals has not yet been considered.

\subsubsection{The Island Rule}

For animals, J. Bristol Foster published a comparative investigation of insular species against their closest mainland relatives in 1964, showing a shift towards gigantism in rodents with a trend towards dwarfism in the larger lagomorphs. For smaller species evolving in insularity, the increasing degree of isolation was proposed to correlate with the increase in body size (Foster, 1964). Termed the 'Island Rule' by Van Valen in 1973, the rule describes the trend for smaller animals to evolve towards gigantism and for larger animals to evolve towards dwarfism (Foster, 1964). The rule was confirmed by Mark Lomolino (2005) in a cross-literary analysis where body size measurements of insular mammals were compared to the body size of species on the mainland, with statistical patterns that conclusively supported the Island Rule with larger bodied taxa on the mainland. Similarities were found in Lindell Bromham and Marcel Cardillo's (2007) study on the Homo floresiensis that compliments the patterns of the Island Rule with the hominid species evolving towards dwarfism in insularity. The applicability of the Island Rule on non-mammalian species shows variation. For reptilian orders, gigantism is viewed in insular iguanids and some lizards, however dwarfism tends to be observed for rattlesnakes (Lomino, 2005). Similarly, birds are observed to obey the Island Rule 
regarding bill size, however the caveat is bill size is often associated with feeding ecology (Clegg \& Owens, 2002).

The applicability of these hypotheses to reoccurring selection for the evolution of flightlessness in insular birds is not known. The purpose of this study is to explore whether flightlessness is a product of one or a mixture of either loss of dispersibility, sizeconstraints, or the island rule. This chapter explores five research questions that investigate the evolution of birds in insularity with comparison to their closest mainland relatives: (1) Is there evidence for the loss of dispersibility? (2) Does loss of dispersibility result from a reduction in wing size? (3) Is the loss of dispersibility associated with a reduction of wing length, an increase in body size, or a combination of both? (4) Is the loss of dispersibility similar between the sexes? (5) Do the changes in wing length and mass co-vary with mainland body size?

\subsection{Methods}

\subsubsection{Study Site}

The super continent Gondwana and predecessor of Pangea encompassed a vast expanse of land recognisable today as continents ranging from South America, through Africa, to Australasia and Antarctica (Gibbs, 2006). Over the past 170 million years, the land that is now known as modern New Zealand became increasingly more isolated via crustal movements and separations, with its terrestrial links to Australia and Antarctica ultimately lost 35 MYA (McLoughlin, 2001). It is during this time, and throughout the geological history of Gondwana and formation of predecessors of the modern continents, flora and fauna experienced an unimaginable growth of evolution that yielded ancestors of many lineages of species that we see on these continents today (Gibbs, 2006). Today, New Zealand is in the Southern Hemisphere, approximately $2000 \mathrm{~km}$ south-east of Australia across the Tasman Sea. New Zealand itself consists of the North Island, South Island, and Stewart Island. In immediate proximity of these three Islands are many smaller offshore islands, separated from the mainland during the rise in sea level in the latter years of the Pleistocene glaciation period (McSaveney, 2007).

This land became home to an incredibly high proportion of endemism in both flora and fauna. These levels of endemism are like that of the Galapagos Islands, commonly known 
to have some of the world's most unique biota (González et al., 2008). A measure of prehuman species endemism in New Zealand yielded substantial results: 95\% of 18,000 insect species, $88 \%$ of land and freshwater birds and $84 \%$ of all flowering plants are considered endemic to New Zealand (Gibbs, 2006, pp. 19).

In addition to high levels of endemism, New Zealand is absent of many of the species that would be expected to be present on these islands, such as many of the mammals found around the globe (Daughtery et al., 1993). At the time of New Zealand's breakaway from Australia, there are records of species in Australia belonging to groups of monotremes, snakes, crocodiles, and land turtles, where none exist in New Zealand today (Gibbs, 2006). New Zealand resembles that of an isolated archipelago due to the lottery of species it gained during its split from other land masses resulting in a vastly unique selection of species that evolved without common selection pressures in other locations. Examples include avian species that have evolved without mammalian predation (McNab, 1994). The well-known Kiwi Apteryx sp. or the Takahe Porphyrio hochstetteri are products of these circumstances with evolved flightlessness (McNab, 1994).

The uniqueness of New Zealand led to it being selected as the focal point to explore the evolutionary causality of flightlessness considering the three hypotheses. With nonmarine or non-migratory avifauna evolving in isolation from populations to that of the other nearest mainland, Australia, New Zealand is home to a plethora of highly endemic and unique species that have acted as a source for over-water dispersion and the foundation of many populations of species on nearby non-Pleistocene offshore islands. These founded populations and colonies on offshore islands and their closest mainland relatives form the subjects of this study. 


\subsubsection{Definitions}

To test the hypotheses, mainland and island geographical categories were established. New Zealand was identified as the mainland, which included the North Island, South Island, and Stewart Island due to being the source of dispersion to the offshore islands for many species. However, this did not include the many surrounding islands in immediate proximity. These islands, such as Kapiti Island, Tiritiri Matangi Island, and Little Barrier Island, were not isolated during the Pleistocene epoch (Figure 3.1). Due to their separation from the mainland being recent on an evolutionary timescale, the populations on these islands have been isolated (if locally restricted) for a duration of time too brief

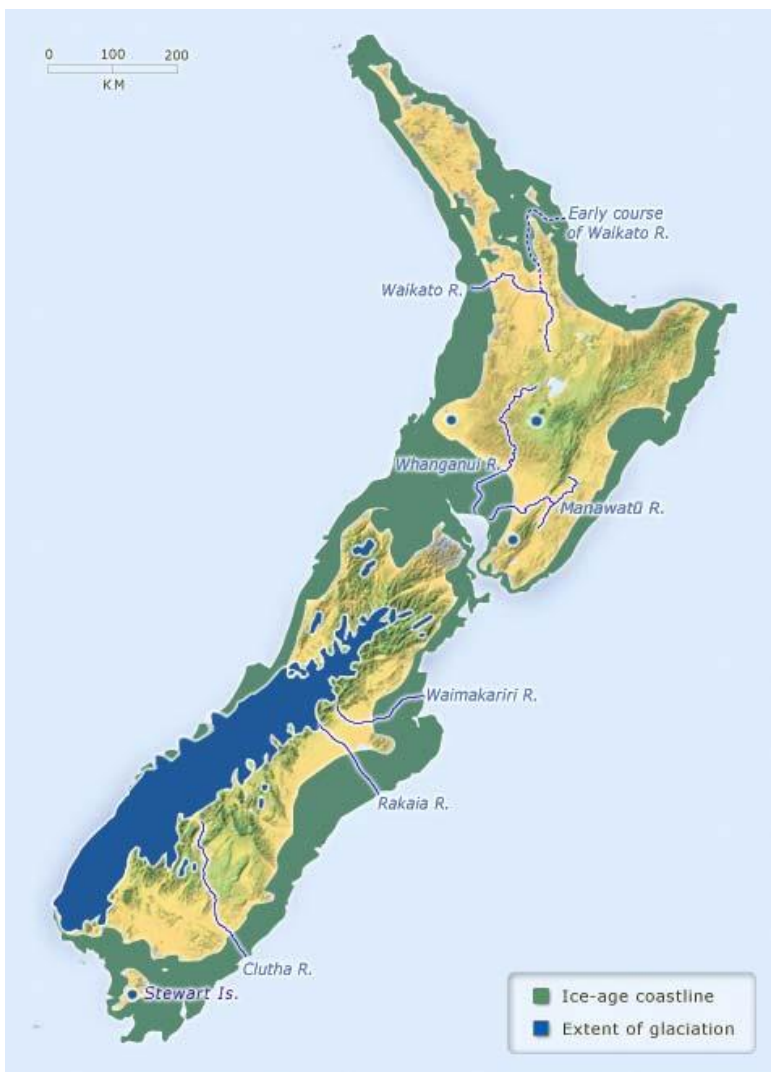

Figure 3.1 Map of New Zealand's coastline during the last glacial period 18,000-20,000 years ago. Retrieved from teara.govt.nz, 23.10.2020. to be recognised as either an insular species or a mainland species.

For the second category of islands, every island within an arbitrarily assigned 2,000 km radius of a fixed point placed approximately on Blenheim, New Zealand, was included in this investigation. Eleven islands were identified to fall within this radius: Antipodes Islands, Auckland Islands, Bounty Islands, Campbell Island, Chatham Islands, Kermadec Islands, Lord Howe Island, Macquarie Island, Norfolk Island, Snares Island, and Three Kings Islands (Figure 3.2). 


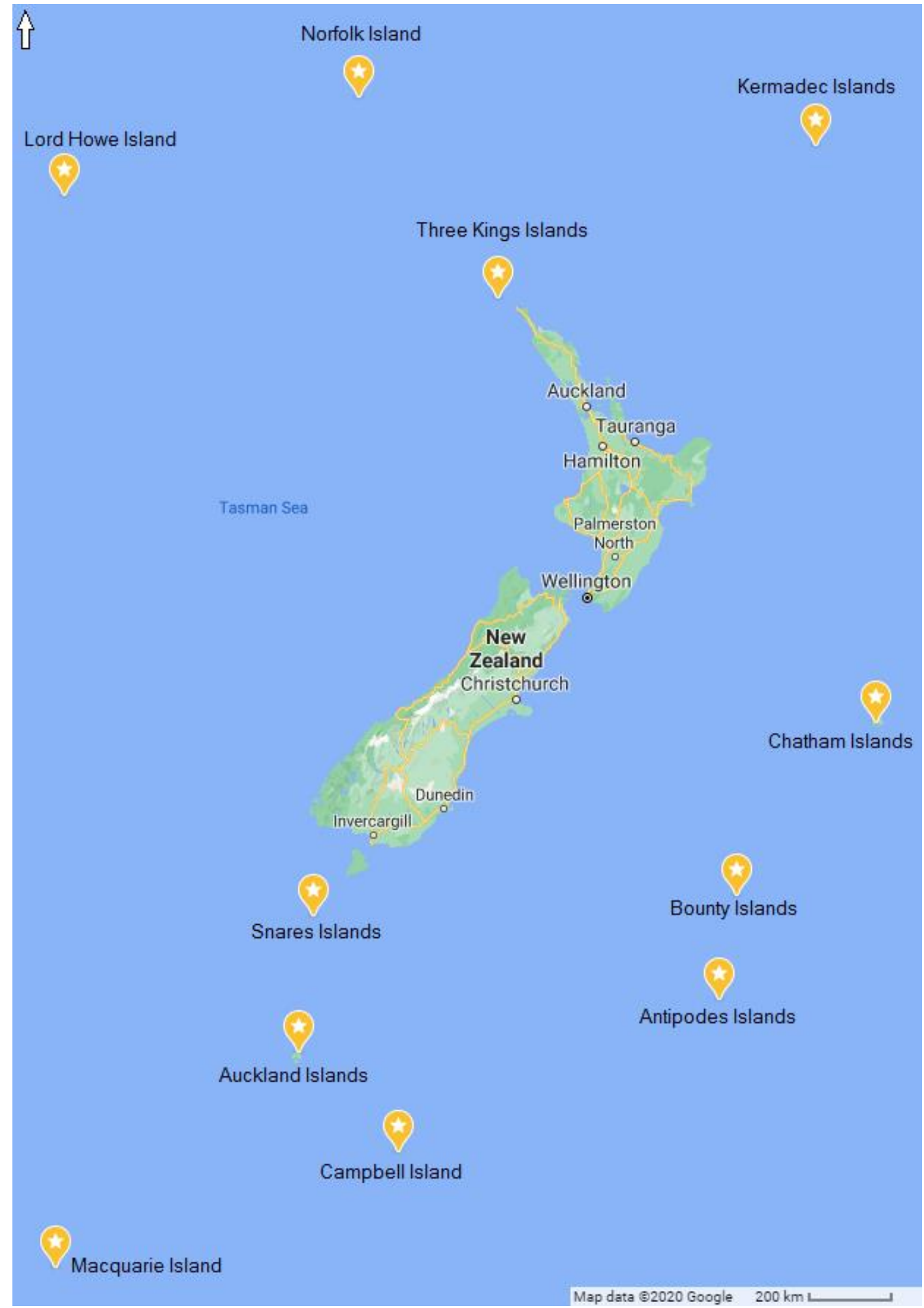

Figure 3.2 Map of New Zealand and offshore islands. Islands of interest have been highlighted with yellow points. Retrieved from Google Maps, 22/10/2020. 


\subsubsection{Species Selection}

Species extant on each of the islands were tabulated to provide a selection of subjects to quantify the effect of their dispersal ability in relation to mainland counterparts. This was sourced via the use of the NZBirdsOnline website, an owned and collaborated project by the Museum of New Zealand Te Papa Tongarewa, the Ornithological Society of New Zealand (Inc.), and the New Zealand Department of Conservation. Each of the offshore islands were searched within this encyclopaedia to identify the extinct and extant permanent resident species that breed on the island. The taxonomic name, common name, as well as the NZBirdsOnline assigned classification that consisted of Introduced and Naturalised, Vagrant, Migratory, Native, and Endemic, were recorded for every species that were returned by the search method.

\subsubsection{Exclusion and Inclusion Criteria}

From the species list attained via the search method, exclusions and inclusions were made to identify truly endemic species that experienced evolution in insularity. Species that fell within the categories Introduced and Naturalised, Vagrant, Migratory, and Native to mainland New Zealand were expelled from the list.

- Introduced and Naturalised species included those that were anthropologically introduced and established self-sustaining populations on the island. Their introduction to these areas would have likely occurred in recent centuries.

- Vagrant species are those that have been recorded by observers to be present in a place outside of their normal distribution, either as victims of involuntary dispersal via events such as storms, or those lost, feeding, or breeding during migration.

- Similarly, migratory species are non-permanent residents of the island. These species, such as the Antarctic tern Sterna vittata breed on many of the islands of interest and are not restricted or confined to the area. The Antarctic tern, however, are not present on a single island year-round, with populations freely mixing with other breeding populations of the same species on other islands.

- Species that are native to New Zealand are those that have naturally dispersed and established sustained populations recently in evolutionary history. These species are considered non-endemic as they are not products of evolutionary pressures 
and selection within New Zealand or the islands. However, the species that are native to the offshore islands but have an endemic mainland New Zealand population were included in this investigation.

In addition to the NZBirds classifications, taxonomic exclusions were made for groups that are non-reliant on terrestrial island habitats, for example species that are largely pelagic or exist within a marine ecosystem. Species that fell within this marine or pelagic category provide uncertainty in the validity of subject species due to the likelihood of occupancy on islands other than those that house breeding colonies, that exist entirely within a marine environment at sea, or those that have a possibility of mixing with populations from other islands. These exclusions included members of the Procellariiforme order, such as the albatross, petrel, mollymawk, taiko, prion, and shearwater. This is due to many members of this order being entirely pelagic with little to no reliance or restriction to terrestrial environments. Similarly, the Stercorariidae (skua), Sternidae (tern, noddy), and Laridae (gull) families were excluded for the same reasons. Additionally, the Sphenisciformes, or penguins, were excluded due to substantial difference in morphology, namely appendage form and function. For island-bound water using species, those that occupy a sub-tidal, inter-tidal, or coastal waters, were also excluded due to non-terrestrial habitat reliance. The focus of this investigation is on land using birds, having evolved synergistically with the island's terrestrial flora and fauna to fill a vacant niche.

Furthermore, several species were excluded due to further constraints. For example, the North Island snipe Coenocorypha aucklandica has been restricted to offshore islands and does not have a mainland population, therefore $C$. a. meinertzhagenae, C. a. aucklandica, C. a. perseverance, C. chathamica, C. pusilla, and C. huegeli were removed. Similarly, several data were unobtainable due to the species being globally extinct and there being no records of wing length or mass. This included the Chatham Island raven Corvus moriorum, Chatham Island bellbird Anthornis melanocephala, Chatham Island coot Fulica chathamensis, Chatham Island fernbird Bowdleria rufescens, Chatham Island rail Cabalus modestus, Chathams Island kaka Nestor chathamensis, Dieffenbach's rail Gallirallus dieffenbachia, Hawkin's rail Diaphorapteryx hawkinsi, New Zealand Corvus antipodum, and the New Zealand little bittern Ixobrychus novaezelandia. Additionally, one species that had non-New Zealand mainland relatives were also removed, the Auckland Island 
rail Lewinia meulleri that is the closest relative of the Australian Lewin's rail Lewinia pectoralis.

Filtering the species lists that were returned from NZBirds searches via the exclusion criteria above yielded a list of land using species entirely endemic to the offshore islands and New Zealand as a mainland (see Appendix 3.6.1).

\subsubsection{Taxon Pairing}

To measure the loss of dispersibility in island species, a mainland counterpart had to be identified to form taxon pairs. The mainland relatives of island species were selected via examining genetic and taxonomic derivations, whether from a common ancestor or directly as a sub-species. This was achieved by examining the entry for the island species within the Handbook of Australian, New Zealand, and Antarctic Birds (HANZAB), on NZBirdsOnline, or from molecular phylogeny literature. Mainland-Island pairings were made via one of four methods:

1. Endemic populations of birds that have the same taxonomic classification on both the island and mainland were paired,

i.e., The Kermadec Island population of Prosthemadera novaeseelandiae was paired with the New Zealand population of Prosthemadera novaeseelandiae.

2. Island subspecies were paired with the mainland at the species level,

i.e., The Antipodes Island Anthus novaeseelandiae steindachneri was paired with the New Zealand Anthus novaeseelandiae.

3. Non-subspecies Island birds with only one mainland relative were paired at the genus level,

i.e., The Chatham Islands Corvus moriorum was paired with the New Zealand Corvus antipodum.

4. Non-subspecies Island birds with multiple mainland relatives at the genus level were paired via molecular phylogeny,

i.e., The Antipodes Island Cyanoramphus unicolor was paired with the New Zealand Cyanoramphus malherbi and not the Cyanoramphus novaezelandiae by the findings of Boon et al., 2000 . 


\subsubsection{Data Collection}

Wing length and mass data were recorded from the literature. The data were predominantly drawn from the HANZAB, where measurements for each of the species were sourced from a range of literature and recorded, averaged, and tabulated. Some gaps in the HANZAB data were filled with measurements taken within other literature. The taxonomic name, common name, averaged wing length, averaged mass, and reference number for each of the samples were recorded for both male and female birds of each of the mainland and island species. Averages of both wing length and mass were taken within a sample, then averaged across samples within a criterion. For example, if multiple populations of a species were measured in different locations throughout New Zealand, all of these were averaged to give a single value representative of a mainland species' wing length or mass.

Further exclusions were implemented during the data collection process to negate sampling errors that may skew or influence results. These involved the removal of all measurements from unsexed birds, juvenile birds, first-year birds, measurements with suspected double sampling, and measurements from birds on Pleistocene split islands. The remaining data that were utilized were adult male and female birds from locations within the established categories of mainland or island. If a species occurred on more than one of the subject islands, these populations were treated as mutually exclusive and gave their own averages for mass and wing length. If an average was not provided in the tables of the HANZAB for a species, one was taken from the measurements available. This set of data operates on the limitations and assumptions that bird weights are a yearly average or are constant through all seasons, as well as all measurements recorded in the HANZAB and literature utilising the same measuring methods and techniques.

For this study we relate reduced dispersal ability to an increased wing-loading ratio, as flight is the method of dispersal for birds and a higher wing loading ratio indicates a poorer flyer and in turn a more ineffective disperser. Wing loading ratios (WLR) were calculated using an alternative approach to common formula found in literature due to the constraints of data availability. The common approach to calculate wing loading ratio is body mass over wing area, as used by Gibb et al. (2006), or Hertel and Ballance's (1999) calculated wing loading ratio with the inclusion of a gravitational constant. For this 
investigation, we refer to wing loading ratio as the mass divided by the length of one wing, a measure of how many $\mathrm{cm}$ of wing per gram of mass and treat this value as a representation of the true wing loading ratio value if wing area data had been available. This is due to the area of a wing correlating strongly with its length.

\subsubsection{Data Analysis}

The research questions explore scaling relationships of morphological traits and sex, testing the hypotheses of isometric scaling or allometric scaling. For all testing, the null hypotheses assume that the true mean difference is equal to zero, indicating that there is a significant likelihood that an isometric relationship is apparent and not an allometric relationship. All analyses were conducted in the $R$ environment with log transformed data. Data displayed visually was graphed with the ggplot and geom_point functions within the tidyverse and ggplot2 packages (R Core Team, 2020).

To test whether taxon pairs overall exhibit isometry or allometry within a feature comparison, linear regressions were calculated using Major Axis (MA) Regression. This was done using the Imodel2 $(y \sim x)$ function within the Imodel2 package. Paired t-testing was also selected as an additional test of statistical significance due to the pair-wise nature of the data between individuals on islands with their closest mainland relative. Paired t-tests were conducted with the t.test function using the native stats package with the paired $=$ TRUE option.

For the Island Rule, the covariance value was calculated with the $\operatorname{cov}(x, y)$ function in the native stats package between mainland mass and increase in mass for island individuals from mainland counterparts, as well as mainland mass against wing length increase for island species from the mainland.

As island populations were paired with their closest mainland relative, it was apparent that double handling of data occurred throughout these analyses. These confounding effects were due to multiple island populations being associated to a single mainland population, therefore within the analyses the single mainland population had its data represented up to five times in a single test. To address this issue, paired t-tests were done using one representative per mainland species with their associated island population. This was replicated five times, due to the maximum of five island populations 
being related to one singular mainland population. All paired t-tests were averaged to examine consistency between whole data analyses and the tests done to exclude confounding effects.

\subsection{Results}

\subsubsection{Acquired Data}

The NZBirdsOnline search method returned a total of 272 extant and extinct populations of species that were or are residents on the eleven islands in this investigation. Of these, 211 populations were excluded from the investigation due to falling within the species exclusion criteria categories of Introduced and Naturalised, Vagrant, Migratory, or Native to New Zealand, along with those that were removed due to taxonomic exclusions. Additionally, a total of 15 endemic species were within the category of water birds and were also removed.

Table 3.1 Total number of populations selected via filtration through the exclusion and inclusion criteria. $\mathbf{n}=$ number of populations.

\begin{tabular}{ll} 
Location & $\boldsymbol{n}$ \\
\hline Antipodes Islands & 4 \\
Auckland Island & 10 \\
Bounty Island & 0 \\
Campbell Island & 2 \\
Chatham Islands & 21 \\
Kermadec Islands & 2 \\
Macquarie Islands & 0 \\
Snares Islands & 3 \\
Three Kings Islands & 1 \\
Norfolk Island & 2 \\
Lord Howe Island & 1 \\
Total: & $\mathbf{4 6}$
\end{tabular}

The remaining 46 populations represent a list of 43 different species and sub-species endemic to New Zealand or each of the eleven islands of interest. Three species were present on more than one island and were counted as individual and separate populations, representatives of the island they inhabit. Not all the study islands had representation within this selection, namely Bounty Island and Macquarie Island. The 
largest proportion of populations within this group are from both the Chatham Islands and Auckland Island (Table 3.1).

All island populations were paired with their closest mainland relative, identified from the literature (see Appendix 3.6.1). Of the 46 island populations a total of 19 mainland populations were identified as closest mainland relatives. The lesser number of mainland populations compared to island species is due to many island populations being paired with the same mainland population, for example the mainland New Zealand pipit Anthus novaeseelandiae is related to three sub-species forming four island populations of pipit. A further 22 species were removed due unobtainable data from extinctions or no recorded measurements.

The remaining 24 populations formed the subjects for analyses. A total of 42 averaged measurements were tabulated for male birds and 39 for female birds. Of the males, 24 averaged measurements were for wing length and 18 for mass. For females, a total of 24 wing length averages were taken along with 15 for mass. Five populations had missing data for both wing length and mass, including four Auckland Island populations of yellowcrowned parakeet Cyanoramphus auriceps, red-crowned parakeet Cyanoramphus novaezelandiae, New Zealand falcon Falco novaeseelandiae, and New Zealand tui Prosthemadera novaeseelandiae, as well as one population of tui from the Kermadec Islands.

Several data were not available from the HANZAB or accessible literature. The remaining 24 populations all had measurements for wing length, however 11 populations had no record of mass for males, females, or both. These species were removed from all analyses involving mass and wing-load ratio, which included one population of tomtit (Petroica macrocephala marrineri) from the Auckland Islands, four populations from the Chatham Islands, the bellbird (Anthornis melanura), red-crowned parakeet (Cyanoramphus novaezelandiae chathamensis), tomtit (Petroica macrocephala chathamensis), and fantail Rhipidura fuliginosa penita); two populations from Snares Island, the fernbird (Bowdleria punctata caudata) and tomtit (Petroica macrocephala dannefaerdi); one population from Three Kings Island, the bellbird (Anthornis melanura obscura); two populations from Norfolk Island, the fantail (Rhipidura fuliginosa pelzelni) and red-crowned parakeet 
(Cyanoramplhus novaezelandiae cookii); as well as the population of red-crowned parakeet (Cyanoramphus novaezelandiae subflavescens) on Lord Howe Island.

\subsubsection{Research Questions}

(1) Is there evidence for the loss of dispersibility?

For island representatives, 13 of the populations had wing loading ratio data for both sexes. A paired t-test was conducted to explore the wing loading ratio of all samples both male and female, for island populations against their closest mainland relative. Both male and female wing loading ratio values were averaged for each population and used in this test. The analysis returned a t-statistic of -3.3743 , a p-value of 0.0055 as well as a confidence interval of -0.1609 to -0.0346 at the $95 \%$ level.

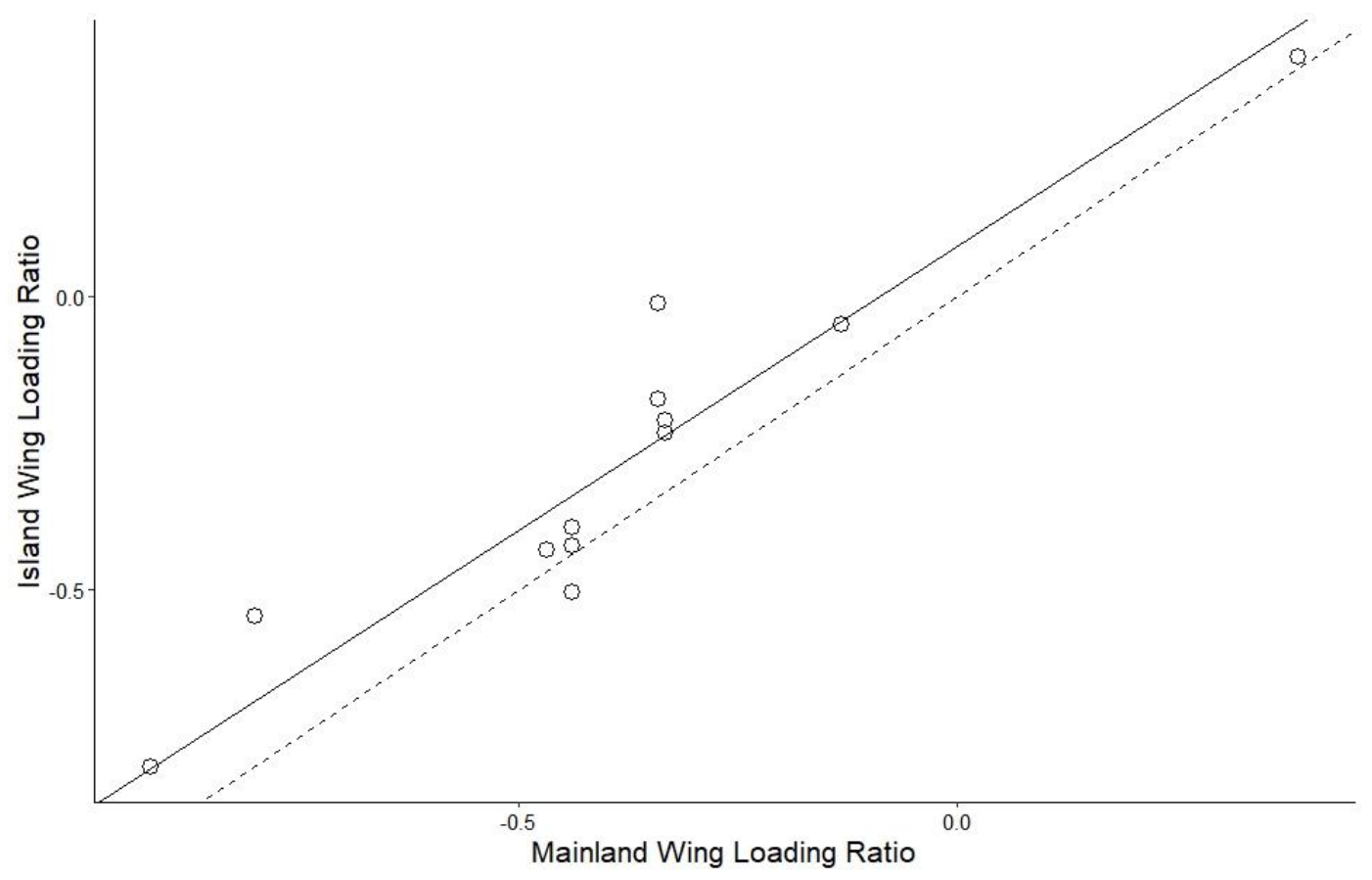

Figure 3.3 The wing loading ratio of mainland birds against island birds. Data points represent a taxon pair of an island population with its closest mainland relative. $X=\log \mathrm{cm} / \mathrm{g}, \mathrm{Y}=\log \mathrm{cm} / \mathrm{g}$. The graph is fitted with a line of isometry (dashed black) and a MA linear regression line (solid black). Taxon pairs display a majority lean towards the islands.

Graphical representation of the data displays a tendency for populations to have a higher wing loading ratio on the islands. The Major Axis (MA) linear regression model gave a 
slope angle of 0.9697 with upper and lower 95\% confidence limits of 0.7617 to 1.2321 with an intercept value of 0.086 and a 95\% confidence interval of 0.0055 to 0.1877 (Figure 3.3).

(2) Does loss of dispersibility result from a reduction in wing size?

To test whether it was mass or wing length that led to the observed trend, both variables were tested individually. A total of 24 pairs of data representing the wing length of birds in island populations paired with their closest mainland relative were analysed using a paired t-test. This resulted in a t-statistic of -4.0321 and a p-value of 0.0005 . The upper and lower limits of the $95 \%$ confidence interval gave values of -0.0517 to -0.0166 . The MA regression produced a slope angle of 1.0182 with upper and lower 95\% confidence limits of 0.8985 to 1.1541 as well as an intercept value of -0.0018 with a confidence interval of -0.2704 to 0.2347 (Figure 3.4).

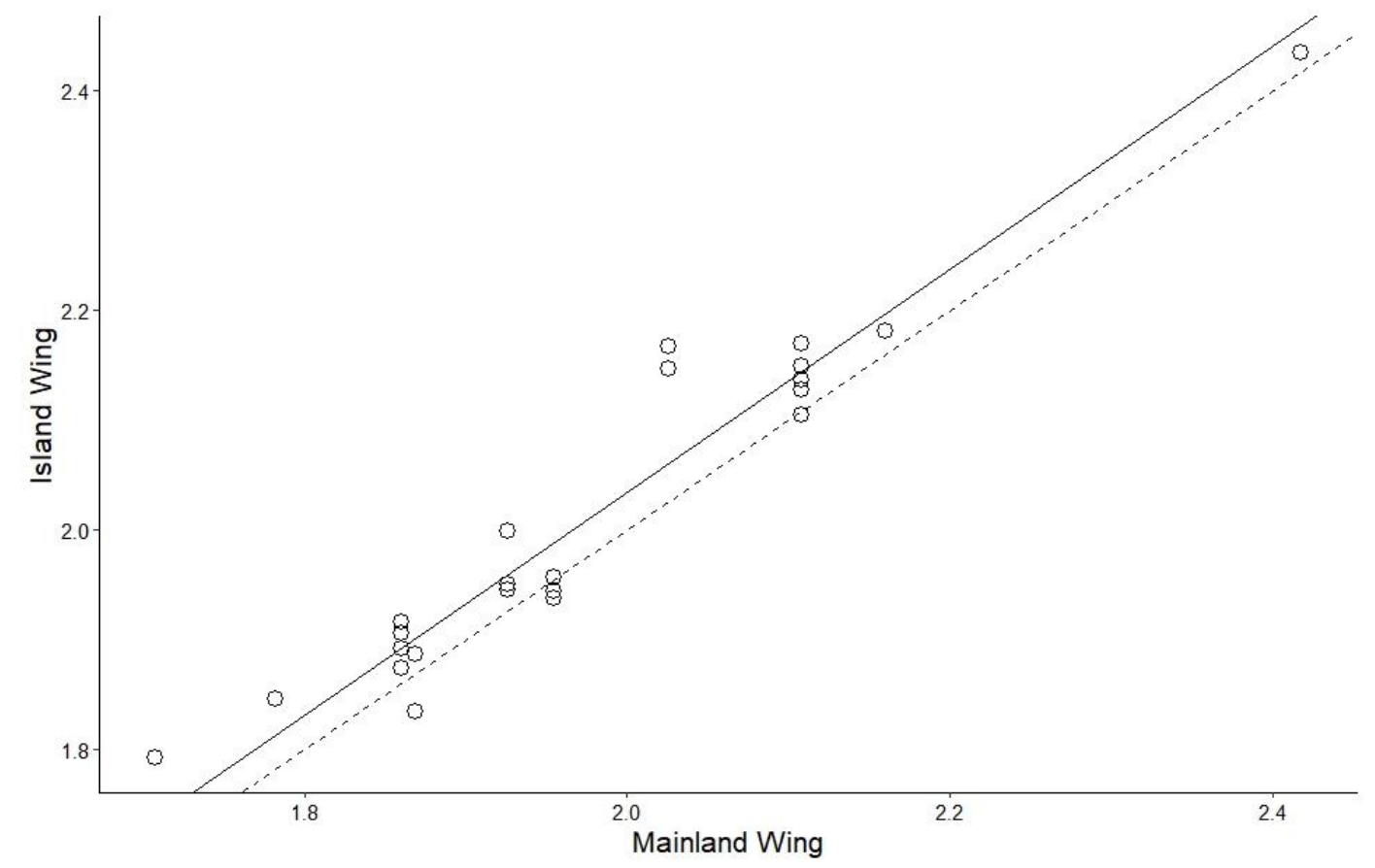

Figure 3.4 The wing length of mainland birds against island birds. Data points represent a taxon pair of an island population with its closest mainland relative. $X=\log \mathrm{cm}, \mathrm{Y}=\log \mathrm{cm}$. The graph is fitted with a line of isometry (dashed black) and a MA linear regression line (solid black). Taxon pairs display a majority lean towards the islands. 
For mass, 13 populations were used in a paired t-test. This resulted in a t-statistic of 3.2476 , a p-value of 0.007 , and a $95 \%$ confidence interval of -0.2231 to -0.0439 . Graphically displayed mass data placed the majority of taxon pairs above the line of isometry with two below the line, leaning towards a greater mass on the islands. The MA regression produced a slope angle of 0.9802 with upper and lower $95 \%$ confidence limits of 0.7868 to 1.2199 as well as an intercept value of 0.1658 with a confidence interval of 0.2238 to 0.48 (Figure 3.5).

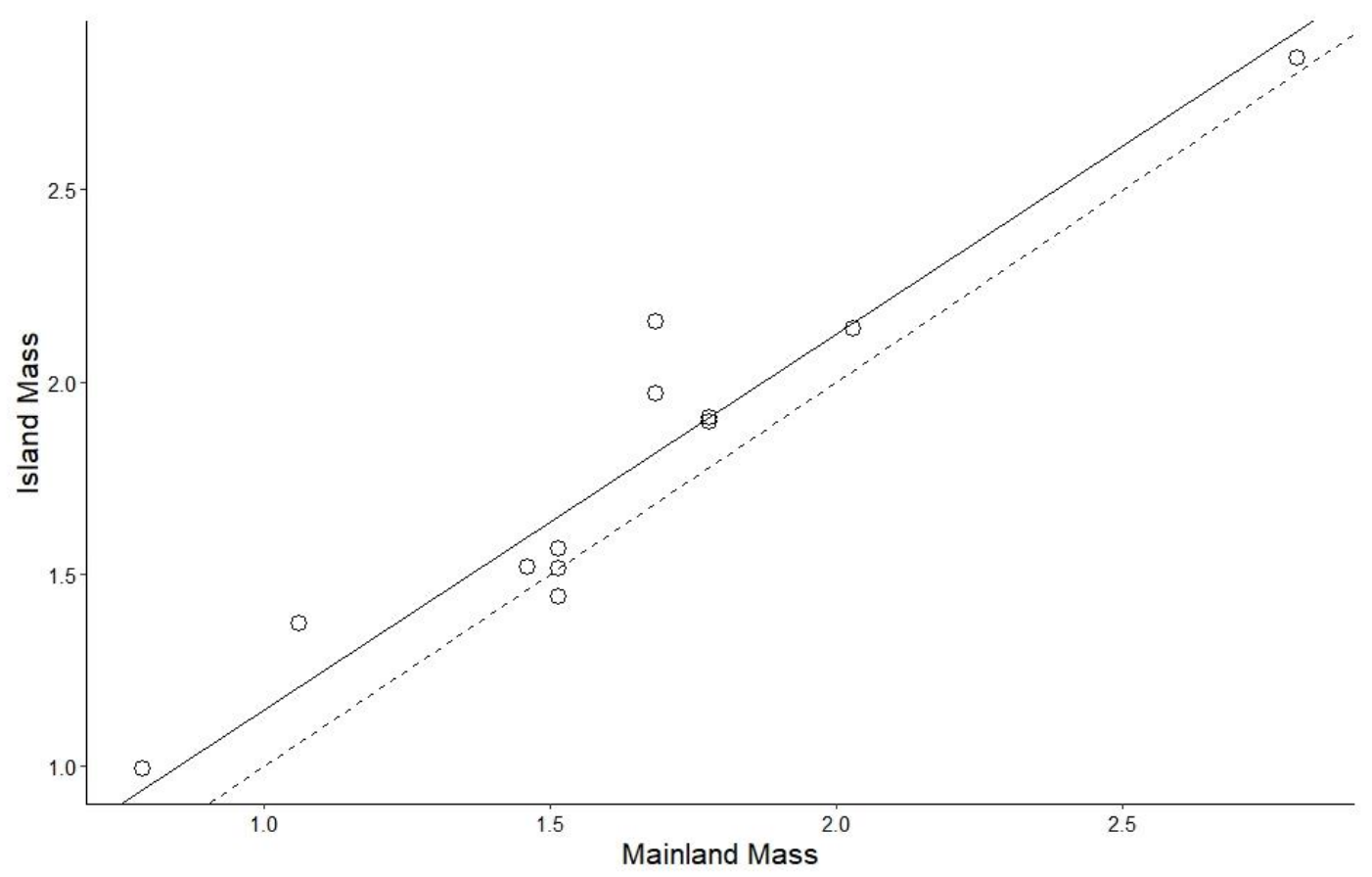

Figure 3.5 The mass of mainland birds against island birds. Data points represent a taxon pair of an island population with its closest mainland relative. $\mathrm{X}=\log \mathrm{g}, \mathrm{Y}=\log \mathrm{g}$. The graph is fitted with a line of isometry (dashed black) and a MA linear regression line (solid black). Taxon pairs display a majority lean towards the islands.

(3) Is the loss of dispersibility associated with a reduction of wing length, an increase in body size, or a combination of both?

The effects of loss of dispersibility were displayed visually to show the change in mass and change in wing lengths between island populations and their closest mainland 
relatives (Figure 3.6). A paired t-test was conducted on this data, resulting on a t-statistic of 3.3594 , a p-value of 0.0057 , and a 95\% confidence interval of 0.0343 to 0.1608 .

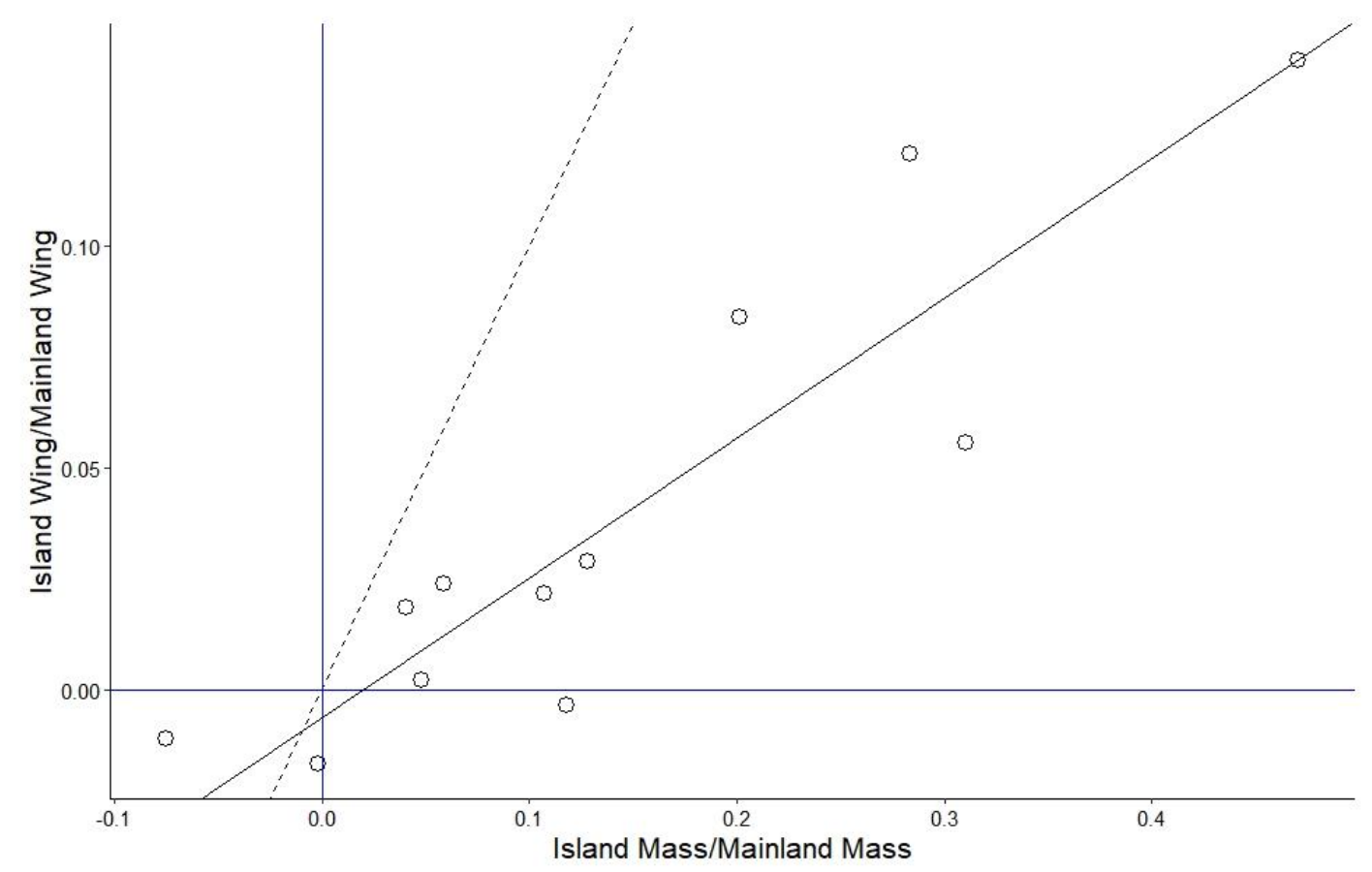

Figure 3.6 Island mass over mainland mass against island wing length over mainland wing length. Data points represent a taxon pair of an island population with its closest mainland relative. $X=\log$ island mass over mainland mass, measured in $\mathrm{g} . \mathrm{Y}=\log$ island wing length over mainland wing length, measured in $\mathrm{cm}$. The graph is fitted with a line of isometry (dashed black), a MA regression line (solid black), as well as a vertical and horizontal reference lines (solid blue).

Of the 13 taxon pairs displayed, the majority are below the line of isometry towards axis of mass, against the one taxon pair leaning toward wing length. This indicates that mass and wing length do not scale isometrically. Two of the taxon pairs showed a decrease in both wing length and mass between the island population and their closest mainland relative. One population displayed a slight decrease in wing length along with an increase in mass, with the remaining taxon pairs showing an increase in both wing length and mass on the islands when compared to their mainland counterpart. The MA regression produced a slope angle of 0.3145 with upper and lower $95 \%$ confidence limits of 0.2194 to 0.415 as well as an intercept value of -0.006 with a confidence interval of -0.0194 to 0.0067 . 
(4) Is the loss of dispersibility similar between the sexes?

To explore if male and female birds display variance in the degree of loss of dispersibility, replicate analyses were done for males compared directly with females. Paired t-tests and MA regression analyses were carried out for the wing loading ratio, wing length, and mass of same-species island male and female birds (Table 3.2, Table 3.3).

Table 3.2 Paired t-test analysis results for Wing Loading Ratio, Wing Length, and Mass for the comparison of male and female island birds.

\begin{tabular}{lrrrr} 
& T-Statistic & p-Value & CI Lower & CI Upper \\
\hline Wing Loading & 1.2857 & 0.2228 & -0.0142 & 0.0549 \\
Wing Length & 5.0897 & $<0.0001$ & 0.0119 & 0.0283 \\
Mass & 2.4319 & 0.0316 & 0.0045 & 0.0814
\end{tabular}

Table 3.3 MA regression results for Wing Loading Ratio, Wing Length, and Mass for the comparison of male and female island birds.

\begin{tabular}{lrrrrrr} 
& Slope & CI Lower & CI Upper & Intercept & CI Lower & CI Upper \\
\hline Wing & 0.9536 & 0.8419 & 1.0793 & -0.0334 & -0.0647 & 0.0018 \\
Wing Length & 0.9928 & 0.9385 & 1.0503 & -0.0056 & -0.1217 & 0.1042 \\
Mass & 0.9723 & 0.8890 & 1.0632 & 0.0063 & -0.1554 & 0.1545
\end{tabular}

The plot to attribute the loss of dispersibility to a change in mass or a change in wing length was replicated for both males and females separately. For both sexes, the majority of the taxon pairs are below the line of isometry towards axis of mass with one leaning to wing length. Two male taxon pairs and one female pair showed a decrease in both wing length with one male population and two female populations displaying a slight decrease in wing length with an increase in mass (Figure 3.7). The remaining pairs showed an increase in both wing length and mass. 


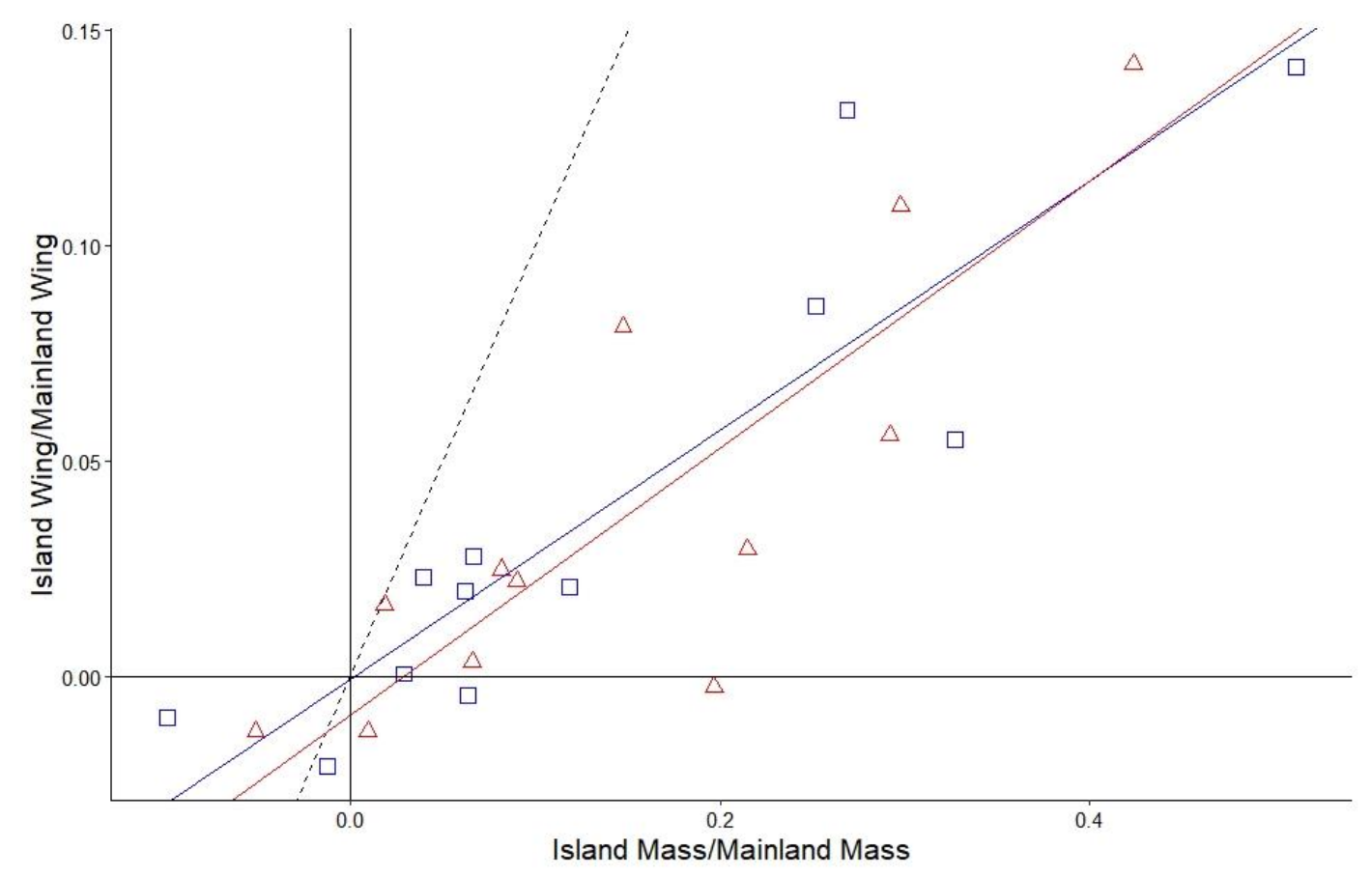

Figure 3.7 Island mass over mainland mass against island wing length over mainland wing length. Data points represent a taxon pair of an island population with its closest mainland relative. $\mathrm{X}=\log$ island mass over mainland mass, measured in $\mathrm{g} . \mathrm{Y}=\log$ island wing length over mainland wing length, measured in $\mathrm{cm}$. Males ( $\square$ ) and Females $(\Delta)$ plotted separately. The graph is fitted with a line of isometry (dashed black), an MA regression line for both males (solid blue) and females (solid red), as well as a vertical and horizontal reference lines (solid black).

A paired t-test for male data resulted with a t-statistic of 2.6987, a p-value of 0.0194 , and a $95 \%$ confidence interval of 0.0175 to 0.1645 . The MA linear regression model for the males gave a slope angle of 0.2889 with upper and lower $95 \%$ confidence limits of 0.1976 to 0.3848 and an intercept value of -0.0004 with a confidence interval of -0.0126 to 0.0112 .

Similarly, the female data paired t-test resulted with a t-statistic of 3.8971, a p-value of 0.0021 , and a $95 \%$ confidence interval of 0.0472 to 0.1669 . The MA linear regression model for the males gave a slope angle of 0.3094 with upper and lower 95\% confidence limits of 0.1814 to 0.4475 and an intercept value of -0.0086 with a confidence interval of -0.0283 to 0.0097 . 
(5) Do the changes in wing length and mass co-vary with mainland body size?

Exploring the concepts of the Island Rule, covariance in mass and wing length changes with the body size of their closest mainland relative displayed slight negative relationships. Island wing length over mainland wing length against mainland mass resulted in a covariance value of -0.0044 . Similarly, island mass over mainland mass against mainland mass gave a covariance value of -0.0152 (Figure 3.8, Figure 3.9).

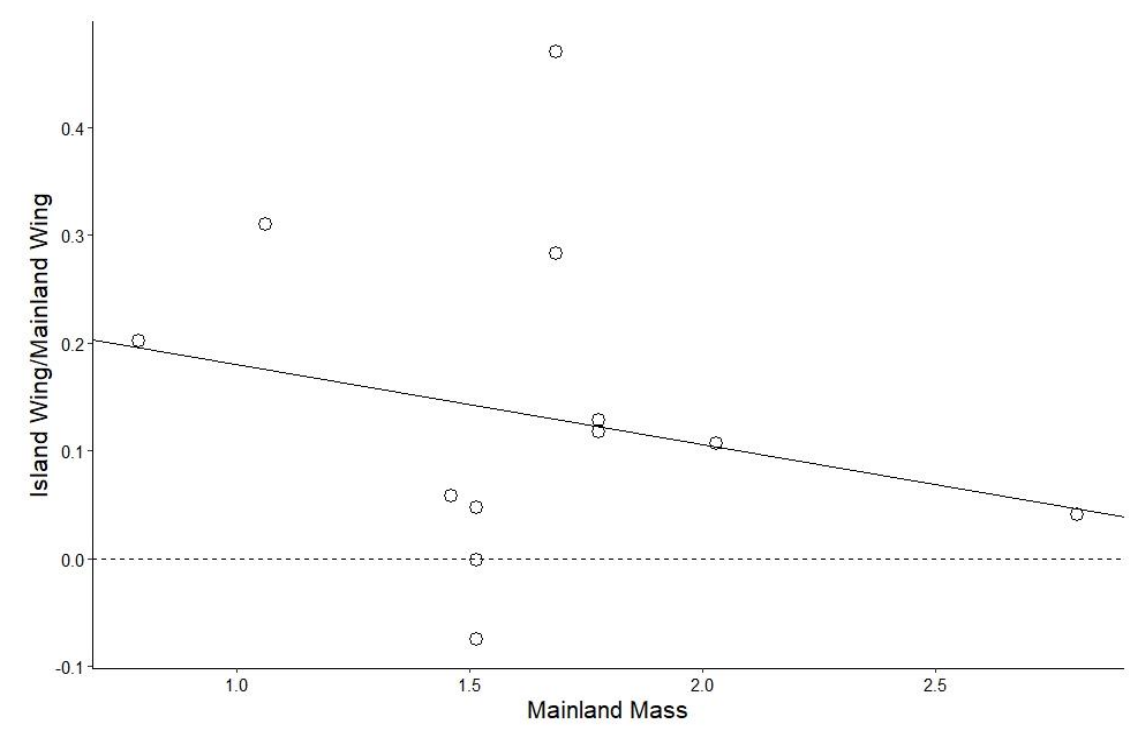

Figure 3.8 Mainland mass against island wing length over mainland wing length. Data points represent a taxon pair of an island population with its closest mainland relative. $\mathrm{X}=\log$ mainland mass, measured in $\mathrm{g}$. $\mathrm{Y}=\log$ island wing length over mainland wing length, measured in $\mathrm{cm}$. The graph is fitted with a horizontal reference line (dashed black) and a MA regression line (solid black). 


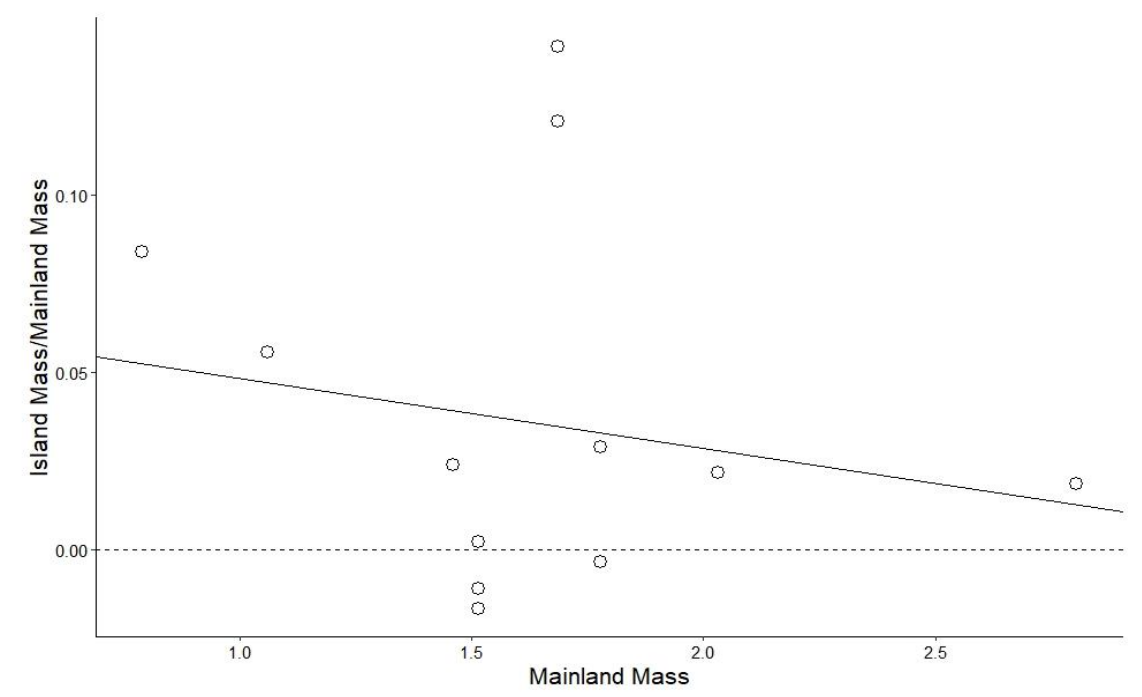

Figure 3.9 Mainland mass against island mass over mainland mass. Data points represent a taxon pair of an island population with its closest mainland relative. $\mathrm{X}=\log$ mainland mass, measured in $\mathrm{g}$. $\mathrm{Y}=\log$ island mass over mainland mass, measured in $\mathrm{g}$. The graph is fitted with a horizontal reference line (dashed black) and a MA regression line (solid black).

When testing for confounding effects, an average of all tests with one population representative per mainland species gave 91\% significant p-values for all paired t-tests, compared to whole data analyses that also resulted in 91\% p-value significance. For these relationships, $100 \%$ of paired t-tests showed consistency in statistical significance and non-significance between whole data analyses and the tests with one population representative per species (Table 3.4).

Table 3.4 Tests for confounding effects on whole data analyses. This table examines each of the analyses for research questions 1 to 5 . \# Sp = the maximum number of populations representative of the same species on the mainland. p1 through p5 are paired t-test p-values with one population representative of each mainland species. $n=$ number of populations used in paired t-test.

\begin{tabular}{|c|c|c|c|c|c|c|c|c|c|c|}
\hline Fig. & \# Sp. & p1 & p2 & p3 & p4 & p5 & $n$ & $\begin{array}{c}\text { Average } \\
\text { p-value }\end{array}$ & $n$ & $\begin{array}{c}\text { Previous } \\
\text { p-value }\end{array}$ \\
\hline 3.3 & 4 & 0.0311 & 0.0158 & 0.0062 & 0.0208 & & 8 & 0.0185 & 13 & 0.0055 \\
\hline 3.4 & 5 & 0.0192 & 0.032 & 0.0052 & 0.0363 & 0.0037 & 10 & 0.0193 & 24 & 0.0005 \\
\hline 3.5 & 4 & 0.0245 & 0.0155 & 0.0062 & 0.0218 & & 8 & 0.017 & 13 & 0.007 \\
\hline 3.6 & 4 & 0.0315 & 0.016 & 0.0063 & 0.021 & & 8 & 0.0187 & 13 & 0.0057 \\
\hline- & 4 & 0.2555 & 0.0331 & 0.2002 & 0.0176 & & 8 & 0.1266 & 13 & 0.2228 \\
\hline- & 5 & 0.0068 & 0.0079 & 0.0134 & 0.007 & 0.0216 & 10 & 0.0113 & 24 & $<0.0001$ \\
\hline- & 4 & 0.0401 & 0.011 & 0.029 & 0.0073 & & 8 & 0.0218 & 13 & 0.0316 \\
\hline 3.7 & 4 & 0.0535 & 0.0268 & 0.0114 & 0.0312 & & 8 & 0.0307 & 13 & 0.0194 \\
\hline 3.7 & 4 & 0.0277 & 0.012 & 0.0081 & 0.0174 & & 8 & 0.0163 & 13 & 0.0021 \\
\hline
\end{tabular}




\subsection{Discussion}

The allometry of flight associated morphological features is evident throughout a range of scaling attributes, such as flight muscles, bone structure, body weight, and flight feathers. Contrary to volant species, flightless birds disobey this allometric scaling with often larger bodies, smaller wings, and reduced flight muscles (Guillemette \& Ouellet, 2005). Furthermore, the dispersal ability of volant species compared to flightless species is substantial, with limitations of dispersal distance determined by wing loading ratios. For successful dispersive or migratory species, individuals require a wing loading ratio low enough for the mechanistic enabling of flight and the sustainability of energy expenditure on the locomotive process. Therefore, a measure of wing loading ratio is an effective means to quantify the dispersal ability of birds. This study investigates the allometric causality of the evolution of flightlessness in insular bird species, within a framework of three alternate hypotheses: Loss of Dispersibility, Size-Constraint, and the Island Rule.

The results of this study indicate that there is evidence for a loss of dispersibility in the surveyed populations that have evolved in insularity. The visual representation of the data displayed an increase in wing loading ratio for island populations, indicating their decrease in flying capability (Figure 3.3). Mainland populations displayed a lower wing loading ratio across most populations with statistical significance ( $\mathrm{p}=0.0055,95 \% \mathrm{CI}=-$ $0.1609,-0.0346)$. Complementary to these findings the MA regression gave a slope angle of 0.9697 with a non-significant confidence interval $(95 \% \mathrm{CI}=0.7617,1.2321)$, indicating that island populations scale isometrically with their mainland counterparts despite a non-isometric intercept $(0.086,95 \% \mathrm{CI}=0.0055,0.1877)$. Conclusively, these data show that wing loading ratios are consistently higher across all island populations with no variance due to the non-isometric intercept with an isometric slope.

Despite confirming a loss of dispersal ability in insular birds, when each variable of mass and wing length are viewed independently the data are conflicting of Darwin's Loss of Dispersibility hypothesis that describes an increased wing loading ratio due to a decrease in wing length. The results reject this hypothesis due to observed isometry in wing length between insular and mainland species. These data hold significance in a paired t-test ( $p$ $=0.0005,95 \% \mathrm{CI}=-0.0517,-0.0166$ ) indicating a significant lean in the data towards an 
increased wing length on islands, yet do not differ from an isometric slope $1.0182,95 \%$ $\mathrm{CI}=0.8985,1.1541)$ and intercept $(-0.0018,95 \% \mathrm{CI}=-0.2704,-0.2347)$ with the application of the MA regression. Complementary to wing length, body mass of island birds a showed a slight increase for insular populations from their mainland counterparts with statistical significance in a paired t-test ( $\mathrm{p}=0.007,95 \% \mathrm{CI}=-0.2231,-0.0439)$, nonsignificance in slope $(0.9802,95 \% \mathrm{CI}=0.7868,1.2199)$, as well as an observed nonsignificant isometric intercept $(0.1658,95 \% \mathrm{CI}=-0.2238,0.48)$ with the MA regression.

For these populations it is observable that there is an increase in wing length and mass, however the rate of change in mass and wing length does not scale isometrically. Comparing the increase in mass with the increase in wing length it is evident that the two scale allometrically, supported with significance in paired t-testing $(\mathrm{p}=0.0057,95 \% \mathrm{CI}=$ $0.0343,0.1608)$. Visual interpretations of this relationship partially complement the Island Rule with an observed increase in both mass and wing length for many species trending towards gigantism (Figure 3.6). However, the data indicates a strong lean towards mass increasing at a rate greater than the rate of increase for wing length, which supports the Size-Constraint hypothesis. The projection of the MA regression model implies an eventual outcome of increased wing loading and loss of dispersal ability due to non-isometric scaling of mass and wing length (slope $=0.3145,95 \% \mathrm{CI}=0.2194$, 0.4150). These findings are consistent for both sexes, as the male to female measure of wing loading ratio, wing length, and mass difference is overwhelmingly insignificant across all measured features (Table 3.3). The strong isometry between male and female for each feature suggests that sex is not a determining factor in the loss of dispersibility for birds evolving in insularity.

The magnitude of change in mass and wing length influenced by the body size of the founding population in this data gives little support for the Island Rule. Both mass and wing length for island species show slight negative covariance with the body size of their mainland counterparts. The increase in mass for island birds is greater for smaller bodied taxa on the mainland ( $\operatorname{cov}=-0.0152)$ and to a lesser degree wing length ( $\operatorname{cov}=-0.044)$. The observed increase in body size for graphed data is consistent with conclusions stating that birds in insularity display an increase in body size due to small birds shifting towards a larger size. 
The support for the Size-Constraint hypothesis is profound with an observed increase in body size and wing length but at a significantly different rate of increase relative to one another. Parallels between the disproportionate increase in body aid relative to wing length may be drawn with the seed size increase and dispersal aid retention in many insular seeds (Burns, 2019). Many plants evolving in insular island habitats display an increase in seed size with no increase in dispersal aid and therefore show a reduction in dispersibility (Burns, 2019). As evident in some study subjects, not all the bird taxon pairs show the same trend of increase with two sub-species of pipit (A. n. steindachneri, A. $n$. chathamensis) showing a decrease in both wing length and body mass. For plants, the loss of dispersal potential is not a highly repeated pattern of evolution and may evolve as a by-product of selection for a larger seed size, which shows consistencies within the subject bird species (Burns, 2019).

For the species in this investigation, it is evident that the Island Rule coupled with the Size-Constraint hypothesis predict projected flightlessness due to an increase in mass disproportionate to the increase in wing length. The MA regression model confirms this with a projected prediction of flightlessness due to this allometric scaling of dispersal influencing traits. When a species ultimately becomes flightless selection favours a reduced wing due to their redundancy - a bird with no wing is presumably more fit due to a reinvestment of energy into positively selected morphological features.

These findings explain the observable patterns in morphological change but not the driving evolutionary and ecological forces that select for flightlessness in insular bird species. Such selective pressures or lack thereof may include the absence of mammalian predators on many of the offshore islands. Predation pressure selects negatively for a species increased wing loading ratio due to the increase in take-off time that, along with flightlessness, is attributed to the reduction in population for many mainland New Zealand birds (Holdaway, 1999). The lesser predation pressure on islands coupled with low raptor species richness potentially releases land birds from requiring large flight muscles that enable rapid escape (Wright et al., 2016).

Species may also experience niche expansion due to a reduction in interspecific competition (Costa et al., 2008). Birds that exist on islands with low species richness utilize a wider variety of habitats and food sources existing in niches unoccupiable on the 
mainland (Wright et al., 2016). Furthermore, the energy conservation hypothesis describes the energetically costly locomotive function of flight could be selected against. As suggested by McCall et al. (1998) the decrease of wing length relative to body mass increases energetic cost of flight. Wright et al. (2016) discovered the reinvestment of energy into other appendages, such as legs, to compensate for reduced flight muscles with findings that suggest birds evolving on islands tend to evolve towards flightlessness even if they remain volant. Additionally, in some songbirds there is evidence for a longer leg having association with increased terrestriality and walking (Wright et al., 2016).

This chapter explored five research questions that investigated the evolution of birds in insularity with comparison to their closest mainland relatives: (1) Is there evidence for the loss of dispersibility? (2) Does loss of dispersibility result from a reduction in wing size? (3) Is the loss of dispersibility associated with a reduction of wing length, an increase in body size, or a combination of both? (4) Is the loss of dispersibility similar between the sexes? (5) Do the changes in wing length and mass co-vary with mainland body size? The results reject a hypothesized observation for a loss of dispersibility due to a reduced wing length in insular birds in favour of the Island Rule and Size-Constraint hypothesis due to a disproportionate increase in mass with wing length indicating a trajectory towards flightlessness. This is consistent between the sexes, and populations overall display a slight negative covariance with increasing mainland body size. However, this study is limited by the small number of focal populations and retrievable data from literary sources. Replication of this study is recommended with a larger pool of data to examine if the findings of this research are consistent across a larger number of populations and species. 


\subsection{References}

Abouheif, E., \& Fairbairn, D. J. (1997). A comparative analysis of allometry for sexual size dimorphism: assessing Rensch's rule. The American Naturalist, 149(3), 540562.

BirdLife International (2017) One in eight of all bird species is threatened with global extinction. Downloaded from http://www.birdlife.org on 19/11/2020.

Boon, W. M., Chambers, G. K., \& Daugherty, C. H. (1999). Genetic analysis of Forbes' parakeet (Cyanoramphus forbesi). Department of Conservation.

Bromham, L., \& Cardillo, M. (2007). Primates follow the 'island rule': implications for interpreting Homo floresiensis. Biology letters, 3(4), 398-400.

Burns, J. G., \& Ydenberg, R. C. (2002). The effects of wing loading and gender on the escape flights of least sandpipers (Calidris minutilla) and western sandpipers (Calidris mauri). Behavioral Ecology and Sociobiology, 52(2), 128-136.

Burns, K. C. (2018). Time to abandon the loss of dispersal ability hypothesis in island plants: A comment on García-Verdugo, Mairal, Monroy, Sajeva and CaujapéCastells (2017). Journal of Biogeography, 45(6), 1219-1222.

Burns, K. C. (2019). Evolution in isolation: the search for an island syndrome in plants. Cambridge University Press.

Campagna, L., McCracken, K. G., \& Lovette, I. J. (2019). Gradual evolution towards flightlessness in steamer ducks. Evolution, 73(9), 1916-1926.

Carlquist, S. (1966a). The biota of long-distance dispersal. II. Loss of dispersibility in Pacific Compositae. Evolution, 20(1), 30-48.

Carlquist, S. (1966b). The biota of long-distance dispersal. III. Loss of dispersibility in the Hawaiian flora. Brittonia, 310-335.

Chen, P., Huang, Z., Zhu, C., Han, Y., Xu, Z., Sun, G., ... \& Ruan, L. (2020). Complete mitochondrial genome and phylogenetic analysis of Gruiformes and Charadriiformes. Pakistan Journal of Zoology, 52(2), 425. 
Clegg, S. M., \& Owens, P. F. (2002). The 'island rule' in birds: medium body size and its ecological explanation. Proceedings of the Royal Society of London. Series B: Biological Sciences, 269(1498), 1359-1365.

Cody, M. L., \& McC, J. (1996). Short-term evolution of reduced dispersal in island plant populations. Journal of Ecology, 53-61.

Costa, G. C., Mesquita, D. O., Colli, G. R., \& Vitt, L. J. (2008). Niche expansion and the niche variation hypothesis: does the degree of individual variation increase in depauperate assemblages?. The American Naturalist, 172(6), 868-877.

Crew, H., \& de Salvio, A. (1991). Galileo Galilei: Dialogues concerning two new sciences. Buffalo, NY: Prometheus Books. (Original work published 1638).

Darwin, C. (1859). On the origin of species by means of natural selection, or, the preservation of favoured races in the struggle for life. London: J. Murray.

Daugherty, C. H., Gibbs, G. W., \& Hitchmough, R. A. (1993). Mega-island or microcontinent? New Zealand and its fauna. Trends in Ecology \& Evolution, 8(12), 437-442.

Dos Remedios, N., Lee, P. L., Burke, T., Székely, T., \& Küpper, C. (2015). North or south? Phylogenetic and biogeographic origins of a globally distributed avian clade. Molecular phylogenetics and evolution, 89, 151-159.

Eileen McSaveney (2007), Glaciers and glaciation - The ice ages, Te Ara - the Encyclopedia of New Zealand, http://www.TeAra.govt.nz/en/map/10737/the-lastglaciation (accessed 17 November 2020)

Foster, J. B. (1964). Evolution of mammals on islands. Nature, 202(4929), 234-235.

Gibb, H., Hjältén, J., Ball, J. P., Pettersson, R. B., Landin, J., Alvini, O., \& Danell, K. (2006). Wing loading and habitat selection in forest beetles: Are red-listed species poorer dispersers or more habitat-specific than common congenerics?. Biological Conservation, 132(2), 250-260.

Gibbs, G. W. (2006). Ghosts of Gondwana: the history of life in New Zealand. Craig Potton Publishing.

Grant, P. R. (1965). The adaptive significance of some size trends in island birds. Evolution, 355-367. 
Guillemette, M., \& Ouellet, J. F. (2005). Temporary flightlessness in pre-laying Common Eiders Somateria mollissima: are females constrained by excessive wingloading or by minimal flight muscle ratio?. Ibis, 147(2), 293-300.

Hedenström, A., \& Møller, A. P. (1992). Morphological adaptations to song flight in passerine birds: a comparative study. Proceedings of the Royal Society of London. Series B: Biological Sciences, 247(1320), 183-187.

Hertel, F., \& Ballance, L. T. (1999). Wing ecomorphology of seabirds from Johnston Atoll. The Condor, 101(3), 549-556.

Holdaway, R. N. (1999). Introduced predators and avifaunal extinction in New Zealand. In Extinctions in near time (pp. 189-238). Springer, Boston, MA.

Hume, J. P., \& Martill, D. (2019). Repeated evolution of flightlessness in Dryolimnas rails (Aves: Rallidae) after extinction and recolonization on Aldabra. Zoological Journal of the Linnean Society, 186(3), 666-672.

Iwaniuk, A. N., Nelson, J. E., James, H. F., \& Olson, S. L. (2004). A comparative test of the correlated evolution of flightlessness and relative brain size in birds. Journal of Zoology, 263(3), 317-327.

Kavanagh, P. H., \& Burns, K. C. (2014). The repeated evolution of large seeds on islands. Proceedings of the Royal Society B: Biological Sciences, 281(1786), 20140675.

Kemp, P., \& Bertness, M. D. (1984). Snail shape and growth rates: evidence for plastic shell allometry in Littorina littorea.Proceedings of the National Academy of Sciences, 81(3), 811-813.

Kirchman, J. J. (2012). Speciation of flightless rails on islands: a DNA-based phylogeny of the typical rails of the Pacific. The Auk, 129(1), 56-69.

Lester, S. E., Ruttenberg, B. I., Gaines, S. D., \& Kinlan, B. P. (2007). The relationship between dispersal ability and geographic range size. Ecology Letters, 10(8), 745-758.

Lomolino, M. V. (2005). Body size evolution in insular vertebrates: generality of the island rule. Journal of Biogeography, 32(10), 1683-1699.

Marchant, S. \& P.J. Higgins (eds) 1990. Handbook of Australian, New Zealand and Antarctic Birds. Volumes 1-7. Oxford University Press, Melbourne. 
McCall, R. A., Nee, S., \& Harvey, P. H. (1998). The role of wing length in the evolution of avian flightlessness. Evolutionary Ecology, 12(5), 569-580.

McLoughlin, S. (2001). The breakup history of Gondwana and its impact on pre-Cenozoic floristic provincialism. Australian Journal of Botany, 49(3), 271-300.

McNab, B. K. (1994). Energy conservation and the evolution of flightlessness in birds. The American Naturalist, 144(4), 628-642.

Meunier, K. (1951). Correlation and redesign in the size relationships between bird wings and bird bodies. Biologia Generalis, 19 , 403-443.

Miller, H. C., \& Lambert, D. M. (2006). A molecular phylogeny of New Zealand's Petroica (Aves: Petroicidae) species based on mitochondrial DNA sequences. Molecular phylogenetics and evolution, 40(3), 844-855.

Museum of New Zealand Te Papa Tongarewa, The Ornithological Society of New Zealand (inc.), and New Zealand Department of Conservation (2013). New Zealand Birds Online, The digital encyclopaedia of New Zealand birds. Retrieved from nzbirdsonline.org.nz.

Poulin, R. (2009). Interspecific allometry of morphological traits among trematode parasites: selection and constraints. Biological Journal of the Linnean Society, 96(3), 533-540.

RStudio Team (2020). RStudio: Integrated Development for R. RStudio, PBC, Boston, MA URL http://www.rstudio.com/.

Rawlence, N. J., Kennedy, M., Scofield, R. P., Tennyson, A. J. D., Boussès, P., \& Chambers, G. K. (2015). Taxonomic status of Cyanoramphus parakeets on the Auckland Islands and implications for the validity of the orange-fronted parakeet as a discrete species. Journal of the Royal Society of New Zealand, 45(4), 197-211.

Sarrus, F. (2017). Sarrus and Rameaux, 1838, translated into 365 English by R. Shour. ResearchGate, 366.

Scholtz, C. H. (2000). Evolution of flightlessness in Scarabaeoidea (Insecta, Coleoptera). Deutsche Entomologische Zeitschrift, 47(1), 5-28.

Shingleton, A. (2010) Allometry: The Study of Biological Scaling. Nature Education Knowledge 3(10):2 
Shour, R. (2019). Why scaling and not dimension, Galileo. Research Gate, 191.

Siegel-Causey, D. (1988). Phylogeny of the Phalacrocoracidae. The Condor, 90(4), 885905.

Sullivan, T. N., Meyers, M. A., \& Arzt, E. (2019). Scaling of bird wings and feathers for efficient flight. Science advances, 5(1), eaat4269.

Terrill, R. S. (2020). Simultaneous Wing Molt as a Catalyst for the Evolution of Flightlessness in Birds. The American Naturalist, 196(6), 000-000.

Trewick, S. A. (1997). Flightlessness and phylogeny amongst endemic rails (Aves: Rallidae) of the New Zealand region. Philosophical Transactions of the Royal Society of London. Series B: Biological Sciences, 352(1352), 429-446.

Trewick, S. A., \& Gibb, G. C. (2010). Vicars, tramps, and assembly of the New Zealand avifauna: a review of molecular phylogenetic evidence. Ibis, 152(2), 226-253.

Van Valen, L. (1973). Patterns and the balance of nature. Evolutionary Theory, 1, 31-49.

Wagner, D. L., \& Liebherr, J. K. (1992). Flightlessness in insects. Trends in Ecology \& Evolution, 7(7), 216-220.

Winter, Y., \& Von Helversen, O. (1998). The energy cost of flight: do small bats fly more cheaply than birds?. Journal of Comparative Physiology B, 168(2), 105-111.

Wright, N. A., Steadman, D. W., \& Witt, C. C. (2016). Predictable evolution toward flightlessness in volant island birds. Proceedings of the National Academy of Sciences, 113(17), 4765-4770.

Zera, A. J., Sall, J., \& Grudzinski, K. (1997). Flight-muscle polymorphism in the cricket Gryllus firmus: muscle characteristics and their influence on the evolution of flightlessness. Physiological zoology, 70(5), 519-529.

Zimmerman, E. C., \& Liebherr, J. K. (1948). Insects of Hawaii: a manual of the insects of the Hawaiian Islands, including an enumeration of the species and notes on their origin, distribution, hosts, parasites, etc (Vol. 16). University of Hawaii Press. 


\subsection{Appendices}

\subsubsection{Taxon Pairings}

Island Species

Antipodes Islands

Anthus novaeseelandiae steindachneri

Coenocorypha aucklandica

meinertzhagenae

Cyanoramphus hochstetteri

Cyanoramphus unicolor
Mainland Relative

New Zealand

Anthus novaeseelandiae

Coenocorypha aucklandica

Anthus novaeseelandiae

Cyanoramphus malherbi

New Zealand

Anthornis melanura

Anthus novaeseelandiae aucklandicus

Coenocorypha aucklandica

Corvus antipodum

Cyanoramphus auriceps

Cyanoramphus novaezelandiae

Falco novaeseelandiae

Lewinia muelleri

Petroica macrocephala marrineri

Prosthemadera novaeseelandiae
Source

HANZAB
HANZAB

HANZAB

NZBirdsOnline
Campbell Island

Anthus novaeseelandiae aucklandicus Coenocorypha aucklandica perseverance
Chatham Islands

Anthornis melanocephala

Anthornis melanura

Anthus novaeseelandiae chathamensis

Bowdleria rufescens

Cabalus modestus

Coenocorypha chathamica

Coenocorypha pusilla

Corvus moriorum

Cyanoramphus forbesi

Cyanoramphus novaezelandiae

chathamensis

Diaphorapteryx hawkinsi

Fulica chathamensis

Gallirallus dieffenbachii

Gerygone albofrontata

Hemiphaga novaeseelandiae

chathamensis

Ixobrychus novaezelandiae

Nestor chathamensis

Petroica macrocephala chathamensis

Petroica traversi

Prosthemadera novaeseelandiae

chathamensis

Rhipidura fuliginosa penita
Anthornis melanura

Anthus novaeseelandiae

Coenocorypha aucklandica

Corvus antipodum

Cyanoramphus auriceps

Cyanoramphus novaezelandiae

Falco novaeseelandiae

South-East Asia Sister Species

Petroica macrocephala

Prosthemadera novaeseelandiae
New Zealand

Anthus novaeseelandiae

Coenocorypha aucklandica

HANZAB

HANZAB
New Zealand

Anthornis melanura

Anthornis melanura

Anthus novaeseelandiae

HANZAB

HANZAB

HANZAB

NZBirdsOnline

Rawlence et al., 2015

Rawlence et al., 2015

HANZAB

Chen et al., 2020

HANZAB

HANZAB
Bowdleria punctata

Gallirallus philippensis

Coenocorypha aucklandica

Coenocorypha aucklandica

Corvus antipodum

Cyanoramphus novaezelandiae

Cyanoramphus novaezelandiae

Gallirallus philippensis

Fulica prisca

Gallirallus philippensis

Gerygone igata

Hemiphaga novaeseelandiae

Ixobrychus novaezelandiae

Nestor meridionalis

Petroica macrocephala

Petroica macrocephala

Prosthemadera novaeseelandiae

Rhipidura fuliginosa
HANZAB
HANZAB
HANZAB
HANZAB
HANZAB
HANZAB
HANZAB

NZBirdsOnline

Boon et al., 1999

Rawlence et al., 2015

Trewick \& Gibb, 2010

NZBirdsOnline

NZBirdsOnline

NZBirdsOnline

HANZAB

NZBirdsOnline

NZBirdsOnline

HANZAB

Miller \& Lambert, 2006

HANZAB

HANZAB 
Kermadec Islands

New Zealand

Cyanoramphus novaezelandiae Cyanoramphus novaezelandiae

Rawlence et al., 2015

cyanurus

Prosthemadera novaeseelandiae

Prosthemadera novaeseelandiae

HANZAB

Snares Islands

New Zealand

Bowdleria punctata caudata

Bowdleria punctata

HANZAB

Coenocorypha huegeli

Coenocorypha aucklandica

HANZAB

Petroica macrocephala dannefaerdi

Petroica macrocephala

HANZAB

Three Kings Islands

New Zealand

Anthornis melanura obscura

Anthornis melanura

HANZAB

Norfolk Island

New Zealand

Cyanoramphus novaezelandiae cookii

Cyanoramphus novaezelandiae

Rawlence et al., 2015

Rhipidura fuliginosa pelzelni

Rhipidura fuliginosa

HANZAB

Lord Howe Island

New Zealand

Cyanoramphus novaezelandiae

Cyanoramphus novaezelandiae

Rawlence et al., 2015

subflavescens 


\subsubsection{Island Data}

\begin{tabular}{|c|c|c|c|c|c|}
\hline Pair & Species & $\begin{array}{c}\text { M Wing } \\
\text { (mm) }\end{array}$ & $\begin{array}{c}\text { F Wing } \\
\text { (mm) }\end{array}$ & $\begin{array}{c}\text { M Mass } \\
\text { (g) }\end{array}$ & $\begin{array}{c}\text { F Mass } \\
\text { (g) }\end{array}$ \\
\hline 1 & Anthus novaeseelandiae steindachneri & 89.60 & 86.00 & 26.40 & 28.70 \\
\hline 2 & Cyanoramphus hochstetteri & 146.00 & 134.00 & 91.00 & 95.10 \\
\hline 3 & Cyanoramphus unicolor & 149.35 & 144.55 & 159.15 & 127.15 \\
\hline 4 & Anthornis melanura & 94.00 & 84.20 & 35.50 & 30.50 \\
\hline 5 & Anthus novaeseelandiae aucklandicus & 91.70 & 89.30 & 35.50 & 37.60 \\
\hline 6 & Petroica macrocephala marrineri & 79.40 & 76.40 & & 14.20 \\
\hline 7 & Anthus novaeseelandiae aucklandicus & 91.70 & 89.30 & 35.50 & 37.60 \\
\hline 8 & Anthus novaeseelandiae chathamensis & 87.30 & 86.00 & 32.23 & 33.00 \\
\hline 9 & Anthornis melanura & 106.40 & 92.80 & & \\
\hline 10 & Cyanoramphus forbesi & 130.10 & 124.25 & 87.00 & 70.00 \\
\hline 11 & Cyanoramphus novaezelandiae chathamensis & 136.50 & 131.40 & 82.50 & \\
\hline 12 & Gerygone albofrontata & 64.67 & 59.10 & 10.72 & 8.85 \\
\hline 13 & Hemiphaga novaeseelandiae chathamensis & 275.20 & 270.20 & 720.00 & 680.00 \\
\hline 14 & Petroica macrocephala chathamensis & 75.97 & 73.57 & & 12.70 \\
\hline 15 & Petroica traversi & 83.10 & 81.55 & 25.00 & 22.00 \\
\hline 16 & Prosthemadera novaeseelandiae chathamensis & 160.85 & 142.90 & 164.13 & 110.27 \\
\hline 17 & Rhipidura fuliginosa penita & 76.00 & 78.00 & 7.60 & \\
\hline 18 & Cyanoramphus novaezelandiae cyanurus & 140.10 & 133.80 & 87.70 & 73.00 \\
\hline 19 & Bowdleria punctata caudata & 70.10 & 69.90 & & \\
\hline 20 & Petroica macrocephala dannefaerdi & 81.30 & 79.40 & 17.05 & \\
\hline 21 & Anthornis melanura obscura & 94.05 & 82.00 & & \\
\hline 22 & Rhipidura fuliginosa pelzelni & 68.67 & 68.00 & 7.00 & \\
\hline 23 & Cyanoramphus novaezelandiae cookii & 145.15 & 137.22 & 100.00 & \\
\hline 24 & Cyanoramphus novaezelandiae subflavescens & 147.00 & 149.00 & & \\
\hline
\end{tabular}




\subsubsection{Mainland Data}

\begin{tabular}{rlrrrr} 
Pair & \multicolumn{1}{c}{ Species } & M Wing & F Wing & M Mass & F Mass \\
(mm) & (mm) & (g) & \multicolumn{1}{c}{ (g) } \\
\hline 1 & Anthus novaeseelandiae & 91.55 & 88.55 & 33.20 & 32.30 \\
2 & Cyanoramphus malherbi & 107.85 & 104.20 & 49.00 & 47.90 \\
3 & Cyanoramphus malherbi & 107.85 & 104.20 & 49.00 & 47.90 \\
4 & Anthornis melanura & 89.14 & 79.50 & 32.40 & 25.27 \\
5 & Anthus novaeseelandiae & 91.55 & 88.55 & 33.20 & 32.30 \\
6 & Petroica macrocephala & 73.20 & 71.68 & 11.77 & 11.23 \\
7 & Anthus novaeseelandiae & 87.75 & 88.55 & 33.20 & 32.30 \\
8 & Anthus novaeseelandiae & 91.55 & 88.55 & 33.20 & 32.30 \\
9 & Anthornis melanura & 89.14 & 79.50 & 32.40 & 25.27 \\
10 & Cyanoramphus novaezelandiae & 131.40 & 124.95 & 75.20 & 44.50 \\
11 & Cyanoramphus novaezelandiae & 131.40 & 124.95 & 75.20 & 44.50 \\
12 & Gerygone igata & 53.05 & 49.00 & 6.00 & 6.30 \\
13 & Hemiphaga novaeseelandiae & 262.80 & 260.00 & 624.00 & 651.80 \\
14 & Petroica macrocephala & 73.20 & 71.68 & 11.77 & 11.23 \\
15 & Petroica macrocephala & 73.20 & 71.68 & 11.77 & 11.23 \\
16 & Prosthemadera novaeseelandiae & 153.25 & 135.80 & 124.90 & 89.60 \\
17 & Rhipidura fuliginosa & 74.90 & 72.80 & 7.80 & 7.70 \\
18 & Cyanoramphus novaezelandiae & 131.40 & 124.95 & 75.20 & 44.50 \\
19 & Bowdleria punctata & 61.50 & 59.60 & 25.10 & 24.00 \\
20 & Petroica macrocephala & 73.20 & 71.68 & 11.77 & 11.23 \\
21 & Anthornis melanura & 89.14 & 79.50 & 32.40 & 25.27 \\
22 & Rhipidura fuliginosa & 74.90 & 72.80 & 7.80 & 7.70 \\
23 & Cyanoramphus novaezelandiae & 131.40 & 124.95 & 75.20 & 44.50 \\
24 & Cyanoramphus novaezelandiae & 131.40 & 124.95 & 75.20 & 44.50
\end{tabular}




\section{Conclusion}

This thesis explored allometry within three different principles: the direct scaling between morphological appendages or features; the differences between the sexes for compared traits; and the geographical influences on allometric relationships of elevation and insularity.

Scaling relationships within morphology were surveyed within the framework of two primary hypotheses. Firstly, Corner's Rule describes the triangular allometric relationship of stem, leaf, and seed size, and secondly, the Loss of Dispersibility hypothesis refers to the reduction of wing length and the increased wing loading ratio of less capable fliers. Within the 50 Coprosma species sampled, there is clear evidence for the allometric scaling of petiole, leaf and seed sizes which confirms the applicability of Corner's Rule. Yet for the birds, evolutionary change in species having evolved in insularity shows a rejection of the Loss of Dispersibility hypothesis due to a disproportionate increase in both wing length and mass for many species. In both circumstances, however, allometric morphology scaling is evident.

The second principle investigated in this thesis involved the differences between the sexes for both plants and birds. Both studies concluded the comparison largely irrelevant to the underlying morphological determinants. For plants, stigma length and filament lengths were found to show no correlation, indicating that the two are entirely mutually exclusive in scaling. This is consistent for the study of birds where loss of dispersibility is identical for both males and females.

Finally, the geographical influences of elevation and insularity were shown to vary. Within the Coprosma genus, allometric scaling of petiole, leaf and seed size is largely unaffected by an increase in elevation, yet for birds, the geographical isolation of island species compared to mainland species shows a distinct trend in change for the allometry of mass and wing length. The contrasting studies of plants and animals provides evidence for allometry existing in vastly different realms of biology. 